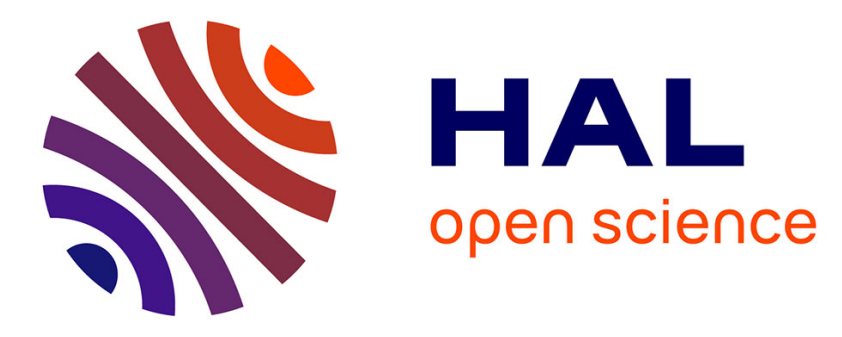

\title{
Imaging-guided precision medicine in non-resectable gastro-entero-pancreatic neuroendocrine tumors: A step-by-step approach
}

Laura Rozenblum, Fatima-Zohra Mokrane, Randy Yeh, Mathieu Sinigaglia, Florent L Besson, Romain-David Seban, Charline Zadro, Lawrence Dierickx, Cecile N Chougnet, Ephraim Partouche, et al.

\section{To cite this version:}

Laura Rozenblum, Fatima-Zohra Mokrane, Randy Yeh, Mathieu Sinigaglia, Florent L Besson, et al.. Imaging-guided precision medicine in non-resectable gastro-entero-pancreatic neuroendocrine tumors: A step-by-step approach. European Journal of Radiology, 2020, 122, pp.108743. 10.1016/j.ejrad.2019.108743 . hal-02988286

\section{HAL Id: hal-02988286 \\ https://hal.sorbonne-universite.fr/hal-02988286}

Submitted on 21 Dec 2021

HAL is a multi-disciplinary open access archive for the deposit and dissemination of scientific research documents, whether they are published or not. The documents may come from teaching and research institutions in France or abroad, or from public or private research centers.
L'archive ouverte pluridisciplinaire HAL, est destinée au dépôt et à la diffusion de documents scientifiques de niveau recherche, publiés ou non, émanant des établissements d'enseignement et de recherche français ou étrangers, des laboratoires publics ou privés.

\section{(ㅇ)(1) $\$$}

Distributed under a Creative Commons Attribution - NonCommerciall 4.0 International 
Imaging-guided precision medicine in non-resectable gastro-entero-pancreatic neuroendocrine tumors: a step-by-step approach

\section{AUTHORS}

Laura Rozenblum $^{1 *}$; Fatima-Zohra Mokrane ${ }^{2,3 *}$; Randy Yeh ${ }^{4}$; Mathieu Sinigaglia ${ }^{5}$; Florent L. Besson ${ }^{6}$; Romain-

David Seban ${ }^{7}$; Charline Zadro ${ }^{2}$; Lawrence Dierickx ${ }^{5}$; Cecile N Chougnet ${ }^{8}$; Ephraim Partouche ${ }^{2}$; Paul RevelMouroz ${ }^{2}$; Binsheng Zhao ${ }^{3}$; Philippe Otal ${ }^{2}$; Lawrence H. Schwartz ${ }^{3}$ : Laurent Dercle ${ }^{3,9}$

\section{AFFILIATIONS}

1. Sorbonne Université, Service de Médecine Nucléaire, AP-HP, Hôpital La Pitié-Salpêtrière, 75013 Paris, France. (NºRCID 0000-0002-6306-8008)

2. Radiology department, Toulouse University Hospital, 1 avenue du Professeur Jean Poulhes, 31059, Toulouse, France.

3. New York Presbyterian Hospital, Columbia University, New York City, New York, USA

4. Memorial Sloan Kettering Cancer Center, Molecular Imaging and Therapy Service. New York, USA

5. Department of Imaging Nuclear Medicine, Institut Claudius Regaud - Institut Universitaire du Cancer de Toulouse - Oncopole, Toulouse, France.

6. Department of Nuclear Medicine, Hopitaux Universitaires Paris-Sud, AP-HP; IR4M UMR 8081 Université Paris-Sud/CNRS, Orsay, France

7. Department of Nuclear Medicine, Institut Curie-René Huguenin, Saint-Cloud, France.

8. Endocrine oncology, Hospital Saint Louis, Paris, France ( ${ }^{\circ}$ ORCID 0000-0001-5092-1201)

9. INSERM U1015, Gustave Roussy Institute, Université Paris-Saclay, Villejuif, F-94805, France

*Contributed equally

\section{CORRESPONDING AUTHOR}

Laura Rozenblum

Service de Médecine Nucléaire

Hôpital La Pitié-Salpêtrière, 75013 Pairs, France

Laura.rozenblum@gmail.com

$+003361822749$ 
Imaging-guided precision medicine in non-resectable gastro-entero-pancreatic neuroendocrine tumors: a step-bystep approach 


\section{ABSTRACT}

The majority of gastroenteropancreatic (GEP) neuroendocrine tumors (NETs) are diagnosed at a non-resectable stage due to non-specific clinical syndromes, late manifestations from mass effects, or incidental detection of a clinically silent disease. Management strategies include curative or cytoreduction surgery, imaging-guided intervention, chemotherapy, immunotherapy, and radionuclide therapies. In this step-by-step review, we provide a structured approach for standardized reading and reporting of medical imaging studies covering content and terminology. This review explains which imaging studies should be used for different NETs and what should be reported when interpreting these studies. This standardized data collection guide should enable precision medicine for the management of patients with GEPNETs of neuroectodermal origin: gastrointestinal-NETs (giNETs) and pancreatic NETs (pNETs). To improve outcomes from GEP-NETs, it contains a comprehensive evaluation of imaging aids for determining surgical non-resectability, and serves as a surrogate measure for tumor differentiation and proliferation, assessing the spatial and temporal heterogeneity of the tumor sites with prognostic and therapeutic implications.

\section{KEYWORDS}

Neuroendocrine tumors; Unresectability; PET-CT; Theranostics; Somatostatin Receptors

Funding: This research did not receive any specific grant from funding agencies in the public, commercial, or not-forprofit sectors. 


\section{ABBREVIATIONS}

ADC Apparent diffusion coefficient

CEUS Contrast enhanced ultra sound examination

CT Computed tomography

DEB Drug-eluting beads

DOPA Dihydroxyphenylalanine

DOTATOC DOTA ${ }^{0}-\mathrm{Phe}^{1}-\mathrm{Tyr}^{3}$ octreotide

ECL Enterochromaffin-like

ENETs European Neuroendocrine Tumor Society

EUS Endoscopic ultra sound examination

18F-FDG 18Fluoro-Fluorodeoxyglucose

68Ga Gallium-68

GEP Gastroenteropancreatic

giNET Gastro-intestinal neuroendocrine tumors

IACIG Intra-arterial injection of calcium

ICM: Immune-checkpoint modulators

If $\alpha$ : Interferon $\alpha$

IOUS Intra operative ultra sound examination

MRI Magnetic resonance imaging

NET Neuroendocrine tumors

OS Overall survival

PD-L1 Programmed death-ligand 1

PET Positron emission tomography

PERCIST PET Response Criteria in Solid Tumors

PFS Progression-free survival

pNET Pancreatic neuroendocrine tumor

PRRT Peptide receptor radionuclide therapy

RECIST Response Evaluation Criteria in Solid Tumors

SIRT Selective internal radiotherapy

SSA Somatostatin analogs

SSTR Somatostatin receptor

SSTR-PET Somatostatin receptor PET

SSTR scintigraphy Somatostatin receptor scintigraphy

SUV Standard uptake value

TAE Transarterial embolization

TACE Transarterial chemoembolization

WHO World Health Organization

Y-90 Yttrium-90 
The progress in medical imaging has led to increase the prevalence of gastroenteropancreatic (GEP) neuroendocrine tumors such as giNETs (gastro-intestinal) and pNET (pancreatic). GEP-NETs are rare tumors but with relatively high prevalence [1], compared to other neoplasms with poor prognosis such as pancreatic ductal adenocarcinoma [2]. This increase is due to a more frequent incidental detection of non-functional NETs [3, 4]. GEPNETs are the most common NET [5]; giNETs are second most prevalent gastrointestinal malignancies; and pNETs represent $1-2 \%$ of all pancreatic neoplasms [6, 7].

At diagnosis, the majority of patients are not eligible to curative surgery, which is reserved for early-stage curable disease [8]. This guide provides a step-by-step approach for standardized reading and propose a standardized imaging case-report form to evaluate response to therapies in unresectable gastroenteropancreatic NETs (GEP-NETs) (Table 1).

\section{RISK STRATIFICATION}

High-risk patients with the poorer prognosis are those with Multiple Endocrine Neoplasia (MEN) syndrome, high tumor grade, and high tumor burden [9, 10]. High-risk patients should be guided toward treatment that is more aggressive. Conversely, therapeutic options should not be exhausted too rapidly in low-risk patients because multiple different treatments with long survival imply that the increasing residual toxicity has to be taken into account (Fig. 1) $[11-13]$.

\section{Embryology}

NETs include three types of heterogeneous epithelial neoplasms: foregut, midgut and hindgut. The embryological origin predicts which molecular imaging approach will achieve the highest diagnostic accuracy (see Table 2) [11] to appraise the tumor burden and resectability.

Foregut NETs (pancreas) are better-explored using somatostatin receptors (SSTR) scintigraphy (Octreoscan) or SSTR PET (nowadays recommended when available) [22]. Indeed, somatostatin receptors 2, 3, and 5 are usually overexpressed on the surfaces of neuroendocrine cells (over 80\%). Therefore, SSTR-scintigraphy targeting ligands imaging has been shown to be useful for staging; determining eligibility for SSTR-based therapy, and monitoring response to therapy in foregut NETs. Depending on the SST analogues used for SSTR 68Ga-PET imaging, this technique presents 81 to $100 \%$ sensitivity for detecting primary pancreatic tumors as well as metastatic disease [14]. For a theranostic purpose, SSR imaging allows a better selection of patients for PPRT [15].

On the other hand, midgut NETs are better explored with 18F-DOPA-PET with a sensitivity of 93-100\% [16]. 18F-DOPA enters neuroendocrine tumors cells via the specific cell membrane bound LAT2 transporter and decarboxylated by the aromatic acid decarboxylase (AADC) to 18F-dopamine [17] (Fig. 5). However, this technique is less specific than SSTR PET and does not allow a theranostic approach.

\section{Hereditary NETs.}

As $15 \%$ of NETs are hereditary, a MEN syndrome should always be ruled out in young patients with or without familial history of cancer. MEN syndrome requires a different management, due to the association with other functional and non-functional NETs observed in the skin, nervous system and smooth muscle tumors [18, 19]. MEN type 1 is a hereditary condition highly associated with rare functional pNETs such as VIPomas, glucagonomas or somatostatinomas. These pNETs are usually malignant, metastatic at diagnosis [3, 20-22], and can be associated with carcinoid syndrome 
$[23,24]$. There is also evidence that MEN syndrome is associated with therapeutically actionable mutations. This is discussed in the section describing imaging-guided response assessment to targeted molecular agents.

Grade.

WHO Classification has recently been updated for pNETs [25, 26] : Grade-1 well-differentiated NETs (G1 NETs); Grade-2 well-differentiated NETs (G2 NETs); Grade-3 well-differentiated NETs (G3 NETs); Grade-3 poorly differentiated neuroendocrine carcinomas (G3 NECs) [27]. G1-NETs are relatively indolent and differentiated from other grades based on their Ki67 or mitotic index, cellular markers for proliferation, mitotic index and differentiation (Fig. 1). Tumor-imaging phenotype can predict tumor grade. High expression of somatostatin receptor, high uptake of amino acids, and low glucose uptake are indicative of a well-differentiated NET with low pathological grade that can guide patient management $[12,28,29]$. On the other hand, 18F-FDG is highly informative for G3 NETs and NECs with Ki$67>20 \%$ since poorly differentiated tumors have a high glucose turnover rate [30]. Moreover, 18F-FDG is more suitable than 68Ga-DOTATATE for G2 tumors with high proliferative capacity (Ki67 $\geq 10 \%$ ) [31]. Those patients could benefit from chemotherapy after PPRT or Somatostatin therapy (Fig. 4).

\section{Tumor functional status.}

Functioning NETs are associated with hormonal syndrome and are observed in up to $40 \%$ of patients [26, 32]. Improvement in imaging has increased the prevalence of nonfunctioning GEP-NETs, which are usually indolent, and are detected either incidentally or due to non-specific symptoms such as pain or mass effects [23]. In non-resectable GEPNETs, a higher morbi-mortality is observed in functioning GEP-NETs as exemplified by the poorer prognosis observed in patients with carcinoid syndrome. Nonfunctioning NETs have unpredictable behavior and a minor risk to metastasize [33] (Fig. 2).

\section{DIAGNOSIS OF NON-RESECTABILITY}

The first step of a precision medicine based approach in non-resectable GEP-NET is to provide imaging evidence that a curative surgical approach is not an option. The imaging of phenotypes of NETs are displayed in Table 23 and Fig 1.

CT, MRI and endoscopic ultrasound are the usual first-line imaging techniques, with high sensitivity (30-80\% and $85 \%$ respectively). Both MRI and CT techniques require a pre-contrast then arterial and portal enhanced acquisitions. GEP-NETs appear typically hypervascular during late arterial phase. CT acquisition must be performed using a thin slice thickness. MRI can help in grading NETs, with ADC (apparent diffusion coefficient) inversely correlated with the tumor grade (Fig. 3). Typical MRI sequences include T2 weighted images, and diffusion images. BILI sequences are used only in case of biliary tract obstruction [8].

\section{II.1. Locoregional staging}

GiNETs.

GiNETs are mostly located in the small bowel, and often go unnoticed. A fibrotic desmoplastic reaction, observed in cases of mesenteric extension, is sometimes the only radiological sign and can preclude resectability [20, 34, 
35]. First-line imaging techniques in GiNET are CT and MRI. Contrast-enhanced CT-enteroclysis, with thin-section acquisition detects up to $94 \%$ of giNETs [35-37]. Alternatively, small bowel MRI \pm enteroclysis can be used, but suffer from intrinsic limitations due to slice thickness and motion artifact [20]. A crucial point is that the optimal imaging techniques depend on giNET location. In rectal giNET, the best preoperative imaging technique is transrectal endoscopic ultrasound, while pelvic MRI is best for T and N staging [38, 39]. For gastric giNETs, exact anatomical location is often challenging both using molecular or anatomical imaging. While endoscopic US are often helpful, only ECLoma type 3 (one of three subtypes), appears as a solitary mass and can be diagnosed by imaging [40-43].

pNETs.

The most frequent functioning pNETS are insulinoma and gastrinomas [21]. Insulinomas are usually intrapancreatic, while gastrinomas can be located anywhere within the "gastrinoma triangle" or other abdominal or extraabdominal organs [59-61]. CT, MRI (with diffusion-weighted imaging sequences), and endoscopic ultrasound for local assessment are considered as first line imaging techniques (Fig. 7). CT and MRI are sensitive for the detection of small pNETs because their hypervascularity can be appraised during the arterial phase [20, 22] (Fig. 2). Intra Operative Ultrasound (IOUS) is a second-line imaging techniques in pNET and should be considered if there is a doubt about resectability since it can diagnose most small pancreatic and peri-pancreatic NET lesions [44]. However, up to $10 \%$ of insulinomas are not detected using conventional imaging [3].

\section{Locoregional extension assessment.}

The evaluation for radiographic evidence of non-resectability includes assessment of perivascular, perineural, mesenteric, and intravascular extensions (Fig. 8). For instance, in pNET, a vascular and perineural involvement can typically precludes resectability [45]. Second, mesenteric extension, also called fibrotic desmoplastic reaction, is observed in up to $75 \%$ of midgut NETs and can cause bowel obstruction [35, 46, 47]. It appears as an irregular soft-tissue mass and is variably associated with central calcifications [34]. Surrounding radiating strands in mesenteric fat are linked with the degree of fibrosis caused by hormonally active substances, like serotonin. Alternatively, diffuse peritoneal studding or ascites is seen. Third, a criterion for locoregional staging is the local vascular evaluation with the differential diagnosis between bland and tumor thrombus: tumor thrombi tend to show imaging patterns identical to primitive lesions on anatomical and functional imaging (e.g., high SSTR expression in tumor thrombi) [48] (Fig. 9).

\section{II.2. Metastatic staging}

Risk of metastatic spread is proportional to size of the primary tumor ( $<1 \mathrm{~cm}$ : $20 \%$ compared to $>2 \mathrm{~cm}$ : $70 \%$ ) [21]. Most frequent metastases are to liver, bone and lung; other common sites are ovaries, breast, skin/subcutaneous, and brain [5] (Fig. 8). Detecting metastases is crucial prior to surgery with curative intent. However, the presence of metastases does not preclude cytoreduction to decrease hormonal symptoms, improve quality-of-life and increase survival. The detection rate of metastases varies with technique. 68Ga-DOTATOC-PET/CT outperforms MRI for the detection of metastatic lymph nodes and pulmonary lesions, whereas MRI is superior for liver and bone lesions (Fig. 4, 10) $[49,50]$.

Liver metastases show a poorer prognosis and are observed in pNETs and giNETS. Liver metastases severely compromise patient quality-of-life by decreasing hepatic metabolism of bioactive hormones, hastening their release into the systemic circulation. Some patients $(\sim 20 \%)$ with liver NETs have limited liver metastases, and can be treated by 
liver surgical or imaging guided resection [19]. The best imaging modalities to evaluate liver metastases are ultrasound and MRI (Fig. 10). Transabdominal ultrasound is predominantly used to guide procedures (thermal ablation therapy or biopsy) due to its low sensitivity (Fig. 11) [20]. Liver metastases are typically hypervascular on arterial phase, but can present with variable enhancement patterns, even within the same patient [34,50-52]. MRI with DWI is the most sensitive imaging technique (95\% sensitivity) [34, 36, 50, 53].

Lung metastases in NETs simulate other lung metastases and are easily diagnosed on CT. They often occur later, explaining the paucity of the "lung metastases alone" situation. For suspicious lung nodules at early stages, diagnosis of metastasis must be cautious, and a biopsy is needed for confirmation and is done after molecular imaging confirmation and multidisciplinary tumor board discussion.

Bone metastases are more frequent when primary lesions are foregut and hindgut NETs [20, 54]. Their diagnosis can be made using anatomical imaging (CT; dedicated MRI) but also using molecular imaging (68Ga-DOTATOCPET/CT) which presents a higher sensitivity and specificity (Fig. 4) [49]. Small sclerotic lesions (rather than lytic or mixed) are frequently encountered and may represent a challenge for CT-image interpretation.

\section{GUIDING SURGICAL APPROACHES IN NON-RESECTABLE PATIENTS}

Palliative surgical debulking is proposed to patients with liver metastases or abdominal lymph nodes and is usually only performed when greater than $90 \%$ of tumor burden can be removed [55]. There is a strong rationale demonstrating that surgical resection in functioning GEP-NETs improves prognosis, quality of life and overall survival [56-58].

A recurrence can occur after surgery. To detect these recurrences, MRI is preferred for liver metastases and metabolic imaging allows whole-body assessment and detection of metastases at distance with higher sensitivity for local-involved lymph nodes [49]. The best timing of surveillance is debated and relies on lifelong surveillance by CT or MRI [59].

\section{GUIDING CYTOREDUCTION OR INTERVENTIONAL APPROACHES IN NON-RESECTABLE PATIENTS}

\section{IV.1. Imaging guided thermal ablation.}

Thermal ablation procedures are frequently used for liver lesions. Imaging guided liver cytoreduction using thermal ablation is indicated in patients with small oligometastatic disease and is as effective as surgery with fewer complications [60-62] (Fig. 12). Liver thermal ablation can also be combined with surgery or other imaging guided interventional approaches, for palliative debulking. While alternative thermal ablation methods such as cryotherapy and microwave-coagulation are extensively used, radiofrequency ablation is the only proven procedure according to international guidelines [55, 63]. MRI remains the preferred technique for the exact assessment of number and location of liver metastases during the treatment-planning phase [51, 61].

Imaging-guided thermal ablation can also be used for oligometastatic lung metastases [61, 62]. Additionally, painful bone metastases can be treated, and pathological fractures in high-risk patients can be prevented using vertebroplasty, kyphoplasty, and osteoplasty [64-66].

\section{IV.2. Intra-arterial interventional radiology.}


Intra-arterial interventional radiology is reserved for symptomatic patients with hepatic-predominant, nonresectable NETs [89]. Pretreatment imaging helps patient assessments and reduces partial treatments rates. Intra-arterial interventional radiology is used in liver metastatic patients since unlike normal liver parenchyma; liver metastases get blood predominantly from the hepatic artery [90].

There are two goals of embolization: provoking tumor ischemia and increasing local drug concentrations by directed intra-arterial chemotherapy [74, 90] (Fig. 11, 12). Tumor ischemia is a proven method of disease control in neuroendocrine liver metastases. Additionally, directed intra-arterial chemotherapy injection allows increasing by more than 20 fold the drug concentrations in the target region compared with intravenous injection [90].

Different embolization techniques have been used in treating liver metastases from NETs. Bland transarterial embolization (TAE) and transcatheter chemoembolization (TACE) with catheter-infused chemotherapy or chemoembolization using drug-eluding beads (DEB TACE) have been reported in the literature [74, 93-96]. Use of each technique (TAE, TACE or DEB-TACE) can be different among institutions. TACE and TAE show similar results for treatment of liver metastatic GI-NETS, as compared to pNETS (better response and improved OS with TACE) [67, 68]. Additionally, CTACE (or TAE in metastases of intestinal origin) is recommended in first intention, rather than DEBTACE, because of higher risk of biliary injuries (caused by ischemia) compared to conventional TACE or TAE [69].

These therapies result in symptom reduction in 50 to $100 \%$ of patients and are reserved for patients with nonresectable hepatic-predominant NETs, especially if they are symptomatic despite targeted therapy [89, 97]. Although some studies have reported an improved survival in patients treated with TAE or TACE, there are no randomized studies to confirm this benefit and comparative studies are needed.

\section{IV.3. Selective internal radiotherapy}

Selective internal radiotherapy (SIRT) with Yttrium-90 (Y-90) microspheres targets multiple sites of disease within the liver using arterially-delivered brachytherapy combined with intra-arterial embolization. Unlike other intraarterial treatments, the numbers and sites of liver metastases do not limit its use. SIRT involves selective intra-arterial catheterization with radioactive microsphere injection under fluoroscopic guidance [70-72]. Recent studies support the use of Y-90 SIRT in unresectable liver metastases, showing an overall objective response rate of $12 \%$ to $90 \%$ and significant improvement in quality-of-life and/or symptoms [70, 73-75]. However, comparative clinical trials are required to prove long-term efficiency [103].

During the work-up phase SIRT treatment simulation is performed few weeks before the actual treatment. First, angiography is performed to evaluate the vascular anatomy of the liver. Then, arterial embolization of hepatic artery branches feeding to the gastro intestinal tract, such as gastroduodenal artery and right gastric artery is performed to prevent Y-90 reflux to GI tract. Finally, Technetium macro-aggregated albumin (same size as Y-90 microspheres) is injected through a selective catheterization mimicking the SIRT procedure. A single-photon-emission CT is performed immediately after, in order to: predict unwanted implantation of microspheres; detect arterio-venous shunts from the hepatic arteries to the pulmonary system or ectopic implantation into the gastrointestinal tract.

\section{GUIDING SYSTEMIC THERAPIES AND THERANOSTIC APPROACHES IN NON-RESECTABLE PATIENTS}




\section{V.1. Internalized vector radiotherapy (IVR)}

Peptide-receptor-radionuclide-therapy (PRRT) is effective for metastatic patients with limited options [76]. ${ }^{90} \mathrm{Y}-$ DOTATOC and ${ }^{177}$ Lu-DOTATATE are the main radiopeptides. Y-90 has high tissue penetration $(11 \mathrm{~mm})$ and is used in large tumors; Lu-177 provides better irradiation of small tumors because of its small tissue-penetration depth ( $2 \mathrm{~mm}$ ) [77]. ENETS guidelines recommended PRRT in G1 and G2 NETs after failure of first-line therapy for patients with high uptake of tracer in all neoplastic foci on pre-treatment SSTR PET [22, 78] (Fig. 13). For lesions with low uptake or large necrosis, PRRT can be done with palliative intent.

Medical imaging is key to evaluate the patient eligibility for PRRT. Examination for treatable lesions using PRRT should be done on both planar and single-photon emission CT images, as was performed in the NETTER-1 trial [79].

Grading of SSTR uptake with Octreoscan using visual Krenning scoring is required for patient selection prior to PRRT [78, 80, 81]. Typically, PRRT is considered when the Krenning score is greater than 2, i.e. an uptake higher than the physiological liver uptake (Fig. 14). As numerous European centers have used SSTR-PET for patient selection; it is important to consider that SSTR-PET/CT result in higher Krenning scores compared to ${ }^{111}$ In-pentetreotide, especially for lesions $\leq 2 \mathrm{~cm}$. However, due to the uncertainty in the risk-benefit of PRRT for small lesions and because this score has not been validated yet for SSTR PET; Krenning scores should be interpreted with caution in these cases [82]. Alternatively, scoring based on dual-tracer imaging (SSRT-PET; FDG-PET) was proposed for patient selection [83]. High SSTR uptake compared to FDG uptake favors PRRT, while high ratios of FDG to SSTR uptake predict resistance to PRRT [84]. Additionally, treatment combinations can be proposed in the future: some authors have combined PRRT with chemotherapy (Capecitabine, 5-FU) in patients with SSTR-positive and FDG-avid disease G3, and achieved clinically relevant disease control with acceptable toxicity [85, 86].

Follow-up of patients treated with PRRT can be challenging, as it induces tumor lysis and cellular-integrity loss rather than tumor-size reduction. However, studies show that decreased SUVmax on 68Ga-DOTATOC-PET may predict responses after 1-2 PRRT cycles [87]. A favorable outcome is expected since both radiopeptides have comparable tumorresponse rates ( 15-35\%), are generally well-tolerated, and have mean PFS of up to 3 years [88]. The NETTER-1 trial evaluated the effects of PRRT on G1 and G2 midgut NETs and showed survival (OS and PFS) and quality-of-life benefits in the Luthatera arm, compared to SST analogs [89, 90].

\section{V.2. Systemic cancer therapies}

During the past decade, the treatment landscape has changed significantly. Figure six show major pathways currently targeted in non-resectable GEP-NETs. Table 1is a template for standardized case-report forms.

\section{Selection of target lesions}

In patients with non-resectable primary tumors, baseline imaging is crucial to assess disease-extent, predict cytoreduction, plan treatment, and guide cytoreduction. MRI is the best technique for liver assessment, while CT and molecular imaging offer a complete cartography of disease extension. Performing several imaging modalities (combining anatomical and molecular imaging) helps characterize disease as significant tumor heterogeneity may co-exist within the same patient, and can prove useful for follow-up (Fig. 4) [5]. While the appearance of a new lesion using a new highly sensitive imaging modality that was not used at baseline (i.e., new PET tracers) could be a progression, it could also be a 
lesion that was previously there but not detected. In this situation, the new lesion cannot be considered as a progression and should rather be considered as a "new baseline lesion" for this new imaging modality.

\section{Response-assessment for chemotherapeutics.}

Several cytotoxic chemotherapeutics are used in metastatic or unresectable NETs/NECs with poor overall survival [91-93]. Tumor shrinkage (vs. growth) on anatomical imaging defines treatment response (vs. failure) to cytotoxic drugs. NETs are predominantly slow-growing tumors and therefore, response assessment using ResponseEvaluation-Criteria-in-Solid-Tumors (RECIST) is limited because tumor burden is stabilized rather than decreased in patients with the best survival [36, 52, 94]. Additionally, tumor size measurements may vary with contrast medium injection protocols on either CT or MRI [36]. Consequently, disease nadir and baseline tumor burden should be used.

\section{Response-assessment in targeted molecular agents.}

Several targeted molecular agents are used. Somatostatin and its synthetic analogs are associated with a high initial symptomatic response, but patients develop resistance to treatment over time [95]. Everolimus and Sunitinib prolong survival for metastatic NETs. Everolimus may be beneficial for unresectable or metastatic well-differentiated and non-functional giNETs $[3,96,97]$. There is a rationale for the therapeutic use of mTOR inhibitors since the serine/threonine kinase 33 (STK33) is responsible for pNETs cells proliferation via the activation of the $\mathrm{PI3K} / \mathrm{AKT} / \mathrm{mTOR}$ pathway [98].

Targeted agents can be cytostatic and alternative definitions of tumor response are explored. In targeted therapies, the predictive value of a change in tumor density (a surrogate of decreased tumor vascularity in NETs hypervascular lesions) on perfusion CT may outperform change in size [94]. Change in tumor density is implemented in Choi criteria (Table 2). Functional imaging techniques may improve treatment response assessments, although there is no recommendation regarding the use of PET Response Criteria in Solid Tumors (PERCIST criteria) (Table 2).

\section{Response assessment in immune-checkpoint modulators.}

Immune-checkpoint modulators (ICMs) such as anti-PD(L)1 and anti-CLTA4 are increasingly used in solid tumors and aim to restore tumor elimination by immune cells. Although there is still no approval of check points inhibitors in NETS, there is a rational suggesting that ICM such as anti- programmed death 1 (PD-1) or its ligand (PDL1) could benefit to GEP-NETs. First, the expression of programmed death-ligand 1 is associated with higher tumor grade (G3) in metastatic GEP-NETs and is predictive and prognostic for survival [41]. Second, ICM are currently under investigation in phase II clinical trials showing promising preliminary results.

The immune checkpoint inhibitor combination of nivolumab and ipilimumab induce a $44 \%$ overall response rate in patients with high-grade neuroendocrine carcinoma - independent to primary and was well tolerated, according to findings from the phase II DART trial. More than half of the patients (56\%) had high-grade disease, and the most common tumor sites were gastrointestinal (47\%).[99] As a comparison, the overall response rate was 0\% in patients with low/intermediate grade tumors independent of primary site.[99] Clinical activity of spartalizumab was evaluated in patients with well-differentiated nonfunctional NET and poorly differentiated GEP NEC. The disease control rate was $57.6 \%$ for pNET, $59.4 \%$ for giNET, and $19.0 \%$ for GEP NEC [100]. 
Because of the distinct mechanisms of ICMs that restore the immune system's anti-tumor capacity, unconventional immune-related phenomena are encountered in terms of tumor response and progression, and adverse events. Radiologists should therefore be aware of new patterns of response and progression to immune therapies [101106]: (i) Hyper-progression defines an acceleration of tumor growth after the initiation of ICM therapy, as compared to the period before treatment initiation used as a reference. Hyperprogression was reported in 9 to $29 \%$ of patients, and was associated with a shorter overall survival; (ii) Pseudo-progression phenomena define a transitory progression in tumor size or metabolism and can mislead the evaluation of cancer treatment efficacy. The pseudo-progression can be due to either delayed therapeutic efficacy or immune cell infiltration; (iii) The abscopal effect defines a response outside of the radiation field when radiation therapy is combined with ICM. The abscopal effect is triggered by several factors such as: the modulation of the expression of molecules on the surface of tumor cells, increased expression of pro-inflammatory cytokines, and enhancement of the recruitment of immune cells; (iv) Immune related adverse events (iRAE) can occur theoretically at any site and at any time in patients treated with ICMs. The most frequent sites are lung, mediastinum lymph nodes (sarcoidosis-like), enterocolitis, hypophysitis, thyroiditis, hepatitis, arthralgia and pancreatitis. Lifethreatening iRAE should be suspected in case of occurrence of pneumonitis and colitis. Medical imaging detects $74 \%$ of irAE in patients treated with anti-PD1 [107] and guides patients and their health care providers towards specific management. In immunotherapy, treatment beyond progression is allowed and iRECIST criteria should be used (Table 2) [108].

\section{USE OF NEW DEVICE, HARDWARE, AND SOFTWARE}

\section{VI.1. Rationale for PET/MRI}

The benefit of PET/MRI for patient outcomes, clinicians and the healthcare system remain to be determined [8]. PET/MRI protocols offer several advantages such as the possibility of one-stop-shopping, which can streamline workflow and patient quality-of-care, lowering dose radiation, advanced motion correction algorithms, and high soft tissue contrast images $[8,109]$. Combination of these two highly sensitive techniques increases detection of lesions in the primary tumor site, and the locoregional extent in the retroperitoneal compartment [110-115]. However, minimizing radiation exposure of patients by replacing CT-scans with MRI and improved staging must be put into perspective in patients with non-resectable GEP-NET since there is no evidence that reducing radiation exposure and detecting additional lesions will dramatically improve patients' survival. Additionally, co-registration of MRI and PET/CT (lower time of acquisition, better cost-effectiveness and more accurate attenuation correction) might be more convenient for several centers than PET/MRI.

Pivotal studies have demonstrated that quantitative imaging biomarkers could be used in patients with solid tumors to predict response to systemic treatment such as targeted therapies and immune checkpoint blockers. This is a very important point to consider in non-resectable GEP-NET since unconventional patterns of response and progression have been observed with these new systemic treatment strategies. PET/MRI could provide alternative response imaging biomarkers. Therefore, one point should be considered when using PET/MRI in precision medicine approaches: CT-scan outperforms MRI for attenuation correction, which is the key role of morphological imaging although several new MRbased approaches have been shown to substantially improve the PET-MRI images quality [116-118]. This needs to be considered when PET is performed to optimize dosimetry planning and should be taken into account for the research of 
radiomics approaches deciphering treatment-induced changes in tumor imaging phenotype since radiomics features are influenced by acquisition protocols [119-124].

\section{VI.2. Rationale for the use of Artificial Intelligence}

There is a rationale suggesting that artificial intelligence could be used in the future to develop signatures designed to optimize the management of patients. The major drawback is that a large amount of well-annotated clinical and imaging data is needed, which restricts its use in GEP-NET patients. The core assumption is that medical images contain quantitative information that could be associated with specific imaging traits to tumor characteristics, prognosis, optimal treatment or tumor response. The current research applications in GEP-NET are diagnosis (differential diagnosis with intrapancreatic accessory spleen, pancreatic ductal adenocarcinomas, pancreatic metastases) [125, 126] and grade prediction[127-130].However, further studies will need to take into account the fact that non-optimal image acquisition may adversely impact the development of imaging signatures [119, 131, 132].

\section{CONCLUSION}

Imaging can guide precision-medicine approaches, personalize patient management and improve quality-of-life and survival for GEP-NETs patients. Imaging can provide a comprehensive non-invasive evaluation of the spatial and temporal heterogeneity of the tumor, and a broad spectrum of information such as stage, grade, non-resectability, behavior, growth potential and sensitivity to treatment of the primary and metastatic disease (Fig. 4). This review provides a structured approach to propose a standardized case-report form responding to clinicians' need (Tables 1-2). 


\section{REFERENCES}

[1] T.A. Ellison, C.L. Wolfgang, C. Shi, J.L. Cameron, P. Murakami, L.J. Mun, A.D. Singhi, T.C. Cornish, K. Olino, Z. Meriden, M. Choti, L.A. Diaz, T.M. Pawlik, R.D. Schulick, R.H. Hruban, B.H. Edil, A single institution's 26-year experience with nonfunctional pancreatic neuroendocrine tumors: a validation of current staging systems and a new prognostic nomogram, Ann Surg 259(2) (2014) 204-12.

[2] R.L. Siegel, K.D. Miller, A. Jemal, Cancer Statistics, 2017, CA Cancer J Clin 67(1) (2017) 7-30.

[3] M. Falconi, B. Eriksson, G. Kaltsas, D.K. Bartsch, J. Capdevila, M. Caplin, B. Kos-Kudla, D. Kwekkeboom, G. Rindi, G. Klöppel, N. Reed, R. Kianmanesh, R.T. Jensen, a.o.V.C.C. Participants, ENETS Consensus Guidelines Update for the Management of Patients with Functional Pancreatic Neuroendocrine Tumors and Non-Functional Pancreatic Neuroendocrine Tumors, Neuroendocrinology 103(2) (2016) 153-171.

[4] P.A. Vagefi, O. Razo, V. Deshpande, D.J. McGrath, G.Y. Lauwers, S.P. Thayer, A.L. Warshaw, C. Fernández-del Castillo, Evolving patterns in the detection and outcomes of pancreatic neuroendocrine neoplasms: the Massachusetts General Hospital experience from 1977 to 2005, Archives of Surgery 142(4) (2007) 347-354.

[5] T.A. Hope, E.K. Bergsland, M.F. Bozkurt, M. Graham, A.P. Heaney, K. Herrmann, J.R. Howe, M.H. Kulke, P.L. Kunz, J. Mailman, L. May, D.C. Metz, C. Millo, S. O'Dorisio, D.L. Reidy-Lagunes, M.C. Soulen, J.R. Strosberg, Appropriate Use Criteria for Somatostatin Receptor PET Imaging in Neuroendocrine Tumors, J Nucl Med 59(1) (2018) 66-74.

[6] R. Canellas, G. Lo, S. Bhowmik, C. Ferrone, D. Sahani, Pancreatic neuroendocrine tumor: Correlations between MRI features, tumor biology, and clinical outcome after surgery, J. Magn. Reson. Imaging 47(2) (2018) 425-432.

[7] J.K. Smith, S.C. Ng, J.S. Hill, J.P. Simons, E.J. Arous, S.A. Shah, J.F. Tseng, T.P. McDade, Complications after pancreatectomy for neuroendocrine tumors: a national study, J Surg Res 163(1) (2010) 63-8.

[8] L. Rozenblum, F.Z. Mokrane, R. Yeh, M. Sinigaglia, F. Besson, R.D. Seban, C.N. Chougnet, P. Revel-Mouroz, B. Zhao, P. Otal, L.H. Schwartz, L. Dercle, The role of multimodal imaging in guiding resectability and cytoreduction in pancreatic neuroendocrine tumors: focus on PET and MRI, Abdom Radiol (NY) (2019).

[9] H. Gouya, O. Vignaux, J. Augui, B. Dousset, L. Palazzo, A. Louvel, S. Chaussade, P. Legmann, CT, Endoscopic Sonography, and a Combined Protocol for Preoperative Evaluation of Pancreatic Insulinomas, American Journal of Roentgenology 181(4) (2003) 987-992.

[10] F.J. Berends, M.A. Cuesta, G. Kazemier, C.H. van Eijck, W.W. de Herder, J.M. van Muiswinkel, H.A. Bruining, H.J. Bonjer, Laparoscopic detection and resection of insulinomas, Surgery 128(3) (2000) 386-391.

[11] T.R. Halfdanarson, K.G. Rabe, J. Rubin, G.M. Petersen, Pancreatic neuroendocrine tumors (PNETs): incidence, prognosis and recent trend toward improved survival, Annals of Oncology 19(10) (2008) 1727-1733.

[12] M.F. Bozkurt, I. Virgolini, S. Balogova, M. Beheshti, D. Rubello, C. Decristoforo, V. Ambrosini, A. Kjaer, R. Delgado-Bolton, J. Kunikowska, W.J.G. Oyen, A. Chiti, F. Giammarile, S. Fanti, Guideline for PET/CT imaging of neuroendocrine neoplasms with (68)Ga-DOTA-conjugated somatostatin receptor targeting peptides and (18)F-DOPA, Eur J Nucl Med Mol Imaging 44(9) (2017) 1588-1601.

[13] A. Berdelou, V. Boige, J. Arfi-Rouche, D. Malka, S. Ederhy, H. Izzedine, S. Leboulleux, C.N. Chougnet, P. Burtin, T. De Baere, Not All Patients with a Pancreatic Neuroendocrine Tumour Will Benefit from All Approved or Recommended Therapeutic Options: A Real-Life Retrospective Study, Neuroendocrinology 105(1) (2017) 26-34. [14] I. Virgolini, M. Gabriel, A. Kroiss, E. von Guggenberg, R. Prommegger, B. Warwitz, B. Nilica, L.G. Roig, M. Rodrigues, C. Uprimny, Current knowledge on the sensitivity of the (68)Ga-somatostatin receptor positron emission tomography and the SUVmax reference range for management of pancreatic neuroendocrine tumours, Eur J Nucl Med Mol Imaging 43(11) (2016) 2072-83.

[15] W.A. Breeman, E. de Blois, H. Sze Chan, M. Konijnenberg, D.J. Kwekkeboom, E.P. Krenning, (68)Ga-labeled DOTA-peptides and (68)Ga-labeled radiopharmaceuticals for positron emission tomography: current status of research, clinical applications, and future perspectives, Semin Nucl Med 41(4) (2011) 314-21.

[16] K.P. Koopmans, E.G. de Vries, I.P. Kema, P.H. Elsinga, O.C. Neels, W.J. Sluiter, A.N. van der Horst-Schrivers, P.L. Jager, Staging of carcinoid tumours with 18F-DOPA PET: a prospective, diagnostic accuracy study, The lancet oncology 7(9) (2006) 728-734.

[17] T. Baumann, C. Rottenburger, G. Nicolas, D. Wild, Gastroenteropancreatic neuroendocrine tumours (GEP-NET) Imaging and staging, Best Pract Res Clin Endocrinol Metab 30(1) (2016) 45-57.

[18] T. Ito, H. Igarashi, H. Uehara, M.J. Berna, R.T. Jensen, Causes of death and prognostic factors in multiple endocrine neoplasia type 1: a prospective study: comparison of $106 \mathrm{MEN1/Zollinger-Ellison} \mathrm{syndrome} \mathrm{patients} \mathrm{with} 1613$ literature MEN1 patients with or without pancreatic endocrine tumors, Medicine (Baltimore) 92(3) (2013) 135-81.

[19] D.S. Foster, R. Jensen, J.A. Norton, Management of liver neuroendocrine tumors in 2018, JAMA Oncol (2018).

[20] R.H. Reznek, CT/MRI of neuroendocrine tumours, Cancer Imaging 6(Spec No A) (2006) S163-S177.

[21] R.T. Jensen, G. Cadiot, M.L. Brandi, W.W. de Herder, G. Kaltsas, P. Komminoth, J.-Y. Scoazec, R. Salazar, A.

Sauvanet, R. Kianmanesh, ENETS Consensus Guidelines for the Management of Patients with Digestive Neuroendocrine Neoplasms: Functional Pancreatic Endocrine Tumor Syndromes, Neuroendocrinology 95(2) (2012) 98-119. 
[22] M. Lipinski, G. Rydzewska, W. Foltyn, E. Andrysiak-Mamos, A. Baldys-Waligorska, T. Bednarczuk, J. BlicharzDorniak, M. Bolanowski, A. Boratyn-Nowicka, M. Borowska, A. Cichocki, J.B. Cwikla, M. Falconi, D. HandkiewiczJunak, A. Hubalewska-Dydejczyk, B. Jarzab, R. Junik, D. Kajdaniuk, G. Kaminski, A. Kolasinska-Cwikla, A. Kowalska, R. Krol, L. Krolicki, J. Kunikowska, K. Kusnierz, P. Lampe, D. Lange, A. Lewczuk-Myslicka, A. Lewinski, M. LondzinOlesik, B. Marek, A. Nasierowska-Guttmejer, E. Nowakowska-Dulawa, J. Pilch-Kowalczyk, K. Poczkaj, V. Rosiek, M. Ruchala, L. Sieminska, A. Sowa-Staszczak, T. Starzynska, K. Steinhof-Radwanska, J. Strzelczyk, K. Sworczak, A. Syrenicz, A. Szawlowski, M. Szczepkowski, E. Wachula, W. Zajecki, A. Zemczak, W. Zgliczynski, B. Kos-Kudla, Gastroduodenal neuroendocrine neoplasms, including gastrinoma - management guidelines (recommended by the Polish Network of Neuroendocrine Tumours), Endokrynol Pol 68(2) (2017) 138-153.

[23] D.C. Metz, R.T. Jensen, Gastrointestinal neuroendocrine tumors: pancreatic endocrine tumors, Gastroenterology 135(5) (2008) 1469-1492.

[24] D. O’Toole, R. Salazar, M. Falconi, G. Kaltsas, A. Couvelard, W.W. de Herder, R. Hyrdel, G. Nikou, E. Krenning, M.-P. Vullierme, Rare functioning pancreatic endocrine tumors, Neuroendocrinology 84(3) (2006) 189-195.

[25] S. Oberndorfer, Karzinoide tumoren des dunndarms, Frankfurt Z Path 1 (1907) 426-432.

[26] K.E. Öberg, Gastrointestinal neuroendocrine tumors, Annals of Oncology 21(suppl_7) (2010) vii72-vii80.

[27] G. Klöppel, D.S. Klimstra, R.H. Hruban, V. Adsay, C. Capella, A. Couvelard, P. Komminoth, S. La Rosa, N. Ohike, R.Y. Osamura, A. Perren, J.-Y. Scoazec, G. Rindi, Pancreatic Neuroendocrine Tumors: Update on the New World Health Organization Classification, AJSP: Reviews \& Reports 22(5) (2017).

[28] S.M. Sadowski, V. Neychev, C. Millo, J. Shih, N. Nilubol, P. Herscovitch, K. Pacak, S.J. Marx, E. Kebebew, Prospective Study of 68Ga-DOTATATE Positron Emission Tomography/Computed Tomography for Detecting GastroEntero-Pancreatic Neuroendocrine Tumors and Unknown Primary Sites, J Clin Oncol 34(6) (2016) 588-96.

[29] I. Buchmann, M. Henze, S. Engelbrecht, M. Eisenhut, A. Runz, M. Schafer, T. Schilling, S. Haufe, T. Herrmann, U. Haberkorn, Comparison of 68Ga-DOTATOC PET and 111In-DTPAOC (Octreoscan) SPECT in patients with neuroendocrine tumours, Eur J Nucl Med Mol Imaging 34(10) (2007) 1617-26.

[30] P. Zhang, J. Yu, J. Li, L. Shen, N. Li, H. Zhu, S. Zhai, Y. Zhang, Z. Yang, M. Lu, Clinical and Prognostic Value of PET/CT Imaging with Combination of 68Ga-DOTATATE and 18F-FDG in Gastroenteropancreatic Neuroendocrine Neoplasms, Contrast media \& molecular imaging 2018 (2018).

[31] P. Zhang, J. Yu, J. Li, L. Shen, N. Li, H. Zhu, S. Zhai, Y. Zhang, Z. Yang, M. Lu, Clinical and Prognostic Value of PET/CT Imaging with Combination of (68)Ga-DOTATATE and (18)F-FDG in Gastroenteropancreatic Neuroendocrine Neoplasms, Contrast Media Mol Imaging 2018 (2018) 2340389.

[32] F. Triponez, D. Dosseh, P. Goudet, P. Cougard, C. Bauters, A. Murat, G. Cadiot, P. Niccoli-Sire, J.A. Chayvialle, A. Calender, C.A. Proye, Epidemiology data on $108 \mathrm{MEN} 1$ patients from the GTE with isolated nonfunctioning tumors of the pancreas, Ann Surg 243(2) (2006) 265-72.

[33] J. Guo, J. Zhao, X. Bi, Z. Li, Z. Huang, Y. Zhang, J. Cai, H. Zhao, Should surgery be conducted for small nonfunctioning pancreatic neuroendocrine tumors: a systematic review, Oncotarget 8(21) (2017) 35368-35375.

[34] C.M. Deroose, E. Hindié, E. Kebebew, B. Goichot, K. Pacak, D. Taïeb, A. Imperiale, Molecular Imaging of Gastroenteropancreatic Neuroendocrine Tumors: Current Status and Future Directions, Journal of Nuclear Medicine 57(12) (2016) 1949-1956.

[35] K.M. Horton, I. Kamel, L. Hofmann, E.K. Fishman, Carcinoid Tumors of the Small Bowel: A Multitechnique Imaging Approach, American Journal of Roentgenology 182(3) (2004) 559-567.

[36] R. Garcia-Carbonero, R. Garcia-Figueiras, A. Carmona-Bayonas, I. Sevilla, A. Teule, M. Quindos, E. Grande, J. Capdevila, J. Aller, J. Arbizu, P. Jimenez-Fonseca, T. Spanish Cooperative Group of Neuroendocrine, Imaging approaches to assess the therapeutic response of gastroenteropancreatic neuroendocrine tumors (GEP-NETs): current perspectives and future trends of an exciting field in development, Cancer Metastasis Rev 34(4) (2015) 823-42.

[37] T. Baumann, C. Rottenburger, G. Nicolas, D. Wild, Gastroenteropancreatic neuroendocrine tumours (GEP-NET) Imaging and staging, Best Pract. Res. Clin. Endocrinol. Metab. 30(1) (2016) 45-57.

[38] J. Wu, R. Srirajaskanthan, J. Ramage, Rectal neuroendocrine tumor, Digestive Endoscopy 26(4) (2014) $532-533$.

[39] A. Kasuga, A. Chino, N. Uragami, T. Kishihara, M. Igarashi, R. Fujita, N. Yamamoto, M. Ueno, M. Oya, T. Muto, Treatment strategy for rectal carcinoids: A clinicopathological analysis of 229 cases at a single cancer institution, Journal of Gastroenterology and Hepatology 27(12) (2012) 1801-1807.

[40] G. KlÖppel, A. Perren, P.U. Heitz, The gastroenteropancreatic neuroendocrine cell system and its tumors: the WHO classification, Annals of the New York Academy of Sciences 1014(1) (2004) 13-27.

[41] J.Y. Kim, S.-M. Hong, J.Y. Ro, Recent updates on grading and classification of neuroendocrine tumors, Annals of Diagnostic Pathology 29 (2017) 11-16.

[42] J.E. Kim, K.T. Lee, J.K. Lee, S.W. Paik, J.C. Rhee, K.W. Choi, Clinical usefulness of carbohydrate antigen 19-9 as a screening test for pancreatic cancer in an asymptomatic population, J Gastroenterol Hepatol 19(2) (2004) 182-6. [43] S. La Rosa, F. Inzani, A. Vanoli, C. Klersy, L. Dainese, G. Rindi, C. Capella, C. Bordi, E. Solcia, Histologic characterization and improved prognostic evaluation of 209 gastric neuroendocrine neoplasms, Human pathology 42(10) (2011) 1373-1384. 
[44] J.A. Norton, T.H. Shawker, J.L. Doppman, D.L. Miller, D.L. Fraker, D.T. Cromack, P. Gorden, R.T. Jensen, Localization and surgical treatment of occult insulinomas, Ann Surg 212(5) (1990) 615-20.

[45] M.H. Kulke, L.B. Anthony, D.L. Bushnell, W.W. De Herder, S.J. Goldsmith, D.S. Klimstra, S.J. Marx, J.L. Pasieka, R.F. Pommier, J.C. Yao, NANETS treatment guidelines: well-differentiated neuroendocrine tumors of the stomach and pancreas, Pancreas 39(6) (2010) 735.

[46] P.K. Woodard, J.M. Feldman, S.S. Paine, M.E. Baker, Midgut carcinoid tumors: CT findings and biochemical profiles, J Comput Assist Tomogr 19(3) (1995) 400-5.

[47] T.R. Bader, R.C. Semelka, V.C. Chiu, D.M. Armao, J.T. Woosley, MRI of carcinoid tumors: spectrum of appearances in the gastrointestinal tract and liver, J Magn Reson Imaging 14(3) (2001) 261-9.

[48] F. Khosa, H.J. Otero, L.M. Prevedello, F.J. Rybicki, D.N. Di Salvo, Imaging Presentation of Venous Thrombosis in Patients With Cancer, American Journal of Roentgenology 194(4) (2010) 1099-1108.

[49] C. Schraml, N.F. Schwenzer, O. Sperling, P. Aschoff, M.P. Lichy, M. Muller, C. Brendle, M.K. Werner, C.D. Claussen, C. Pfannenberg, Staging of neuroendocrine tumours: comparison of [(6)(8)Ga]DOTATOC multiphase PET/CT and whole-body MRI, Cancer Imaging 13 (2013) 63-72.

[50] G. d'Assignies, P. Fina, O. Bruno, M.P. Vullierme, F. Tubach, V. Paradis, A. Sauvanet, P. Ruszniewski, V. Vilgrain, High sensitivity of diffusion-weighted MR imaging for the detection of liver metastases from neuroendocrine tumors: comparison with T2-weighted and dynamic gadolinium-enhanced MR imaging, Radiology 268(2) (2013) 390-9.

[51] C. Dromain, T. de Baere, J. Lumbroso, H. Caillet, A. Laplanche, V. Boige, M. Ducreux, P. Duvillard, D. Elias, M. Schlumberger, R. Sigal, E. Baudin, Detection of liver metastases from endocrine tumors: a prospective comparison of somatostatin receptor scintigraphy, computed tomography, and magnetic resonance imaging, J. Clin. Oncol. 23(1) (2005) 70-78.

[52] A. Sundin, U. Garske, H. Örlefors, Nuclear imaging of neuroendocrine tumours, Best Practice \& Research Clinical Endocrinology \& Metabolism 21(1) 69-85.

[53] H.J. Kim, S.S. Lee, J.H. Byun, J.C. Kim, C.S. Yu, S.H. Park, A.Y. Kim, H.K. Ha, Incremental value of liver MR imaging in patients with potentially curable colorectal hepatic metastasis detected at CT: a prospective comparison of diffusion-weighted imaging, gadoxetic acid-enhanced MR imaging, and a combination of both MR techniques, Radiology 274(3) (2015) 712-22.

[54] D. Putzer, M. Gabriel, B. Henninger, D. Kendler, C. Uprimny, G. Dobrozemsky, C. Decristoforo, R.J. Bale, W. Jaschke, I.J. Virgolini, Bone metastases in patients with neuroendocrine tumor: 68Ga-DOTA-Tyr3-octreotide PET in comparison to CT and bone scintigraphy, Journal of Nuclear Medicine 50(8) (2009) 1214-1221.

[55] M. Orditura, A. Petrillo, J. Ventriglia, A. Diana, M.M. Laterza, A. Fabozzi, B. Savastano, E. Franzese, G. Conzo, L. Santini, F. Ciardiello, F. De Vita, Pancreatic neuroendocrine tumors: Nosography, management and treatment, Int J Surg 28 Suppl 1 (2016) S156-62.

[56] J.P. Boudreaux, D.S. Klimstra, M.M. Hassan, E.A. Woltering, R.T. Jensen, S.J. Goldsmith, C. Nutting, D.L. Bushnell, M.E. Caplin, J.C. Yao, S. North American Neuroendocrine Tumor, The NANETS consensus guideline for the diagnosis and management of neuroendocrine tumors: well-differentiated neuroendocrine tumors of the Jejunum, Ileum, Appendix, and Cecum, Pancreas 39(6) (2010) 753-766.

[57] L.H. Tang, O. Basturk, J.J. Sue, D.S. Klimstra, A Practical Approach to the Classification of WHO Grade 3 (G3)

Well Differentiated Neuroendocrine Tumor (WD-NET) and Poorly Differentiated Neuroendocrine Carcinoma (PD-NEC) of the Pancreas, The American journal of surgical pathology 40(9) (2016) 1192-1202.

[58] L.H. Tang, J. Shia, R.A. Soslow, D. Dhall, W.D. Wong, E. O'Reilly, J. Qin, P. Paty, M.R. Weiser, J. Guillem, Pathologic classification and clinical behavior of the spectrum of goblet cell carcinoid tumors of the appendix, The American journal of surgical pathology 32(10) (2008) 1429-1443.

[59] E. Merola, M.E. Pavel, F. Panzuto, G. Capurso, N. Cicchese, A. Rinke, T.M. Gress, E. Iannicelli, D. Prosperi, P. Pizzichini, V. Prasad, P. Kump, R. Lipp, S. Partelli, M. Falconi, B. Wiedenmann, G. Delle Fave, Functional Imaging in the Follow-Up of Enteropancreatic Neuroendocrine Tumors: Clinical Usefulness and Indications, J Clin Endocrinol Metab 102(5) (2017) 1486-1494.

[60] J. Eriksson, P. Stålberg, A. Nilsson, J. Krause, C. Lundberg, B. Skogseid, D. Granberg, B. Eriksson, G. Åkerström, P. Hellman, Surgery and Radiofrequency Ablation for Treatment of Liver Metastases from Midgut and Foregut Carcinoids and Endocrine Pancreatic Tumors, World J Surg 32(5) (2008) 930-938.

[61] T. de Baère, A. Aupérin, F. Deschamps, P. Chevallier, Y. Gaubert, V. Boige, M. Fonck, B. Escudier, J. Palussiére, Radiofrequency ablation is a valid treatment option for lung metastases: experience in 566 patients with 1037 metastases, Annals of Oncology 26(5) (2015) 987-991.

[62] T. de Baere, J. Palussiere, A. Auperin, A. Hakime, M. Abdel-Rehim, M. Kind, C. Dromain, A. Ravaud, N. Tebboune, V. Boige, D. Malka, C. Lafont, M. Ducreux, Midterm local efficacy and survival after radiofrequency ablation of lung tumors with minimum follow-up of 1 year: prospective evaluation, Radiology 240(2) (2006) 587-96. [63] T.J. Vogl, T. Gruber, N.N.N. Naguib, R. Hammerstingl, N.-E.A. Nour-Eldin, Liver metastases of neuroendocrine tumors: treatment with hepatic transarterial chemotherapy using two therapeutic protocols, American Journal of Roentgenology 193(4) (2009) 941-947. 
[64] G. Sun, P. Jin, X.-w. Liu, M. Li, L. Li, Cementoplasty for managing painful bone metastases outside the spine, Eur Radiol 24(3) (2014) 731-737.

[65] G.C. Anselmetti, A. Manca, C. Ortega, G. Grignani, F. Debernardi, D. Regge, Treatment of extraspinal painful bone metastases with percutaneous cementoplasty: a prospective study of 50 patients, Cardiovasc Intervent Radiol 31(6) (2008) 1165-73.

[66] A. Gangi, S. Guth, J.P. Imbert, H. Marin, J.L. Dietemann, Percutaneous vertebroplasty: indications, technique, and results, RadioGraphics 23(2) (2003) e10.

[67] F. Maire, C. Lombard-Bohas, D. O'Toole, M.P. Vullierme, V. Rebours, A. Couvelard, A.L. Pelletier, M. Zappa, F. Pilleul, O. Hentic, P. Hammel, P. Ruszniewski, Hepatic arterial embolization versus chemoembolization in the treatment of liver metastases from well-differentiated midgut endocrine tumors: a prospective randomized study, Neuroendocrinology 96(4) (2012) 294-300.

[68] S. Gupta, M.M. Johnson, R. Murthy, K. Ahrar, M.J. Wallace, D.C. Madoff, S.E. McRae, M.E. Hicks, S. Rao, J.N. Vauthey, J.A. Ajani, J.C. Yao, Hepatic arterial embolization and chemoembolization for the treatment of patients with metastatic neuroendocrine tumors: variables affecting response rates and survival, Cancer 104(8) (2005) 1590-602. [69] B. Guiu, F. Deschamps, S. Aho, F. Munck, C. Dromain, V. Boige, D. Malka, S. Leboulleux, M. Ducreux, M. Schlumberger, E. Baudin, T. de Baere, Liver/biliary injuries following chemoembolisation of endocrine tumours and hepatocellular carcinoma: lipiodol vs. drug-eluting beads, J Hepatol 56(3) (2012) 609-17.

[70] A. Deleporte, P. Flamen, A. Hendlisz, State of the art: radiolabeled microspheres treatment for liver malignancies, Expert Opin Pharmacother 11(4) (2010) 579-586.

[71] A. Kennedy, L. Bester, R. Salem, R.A. Sharma, R.W. Parks, P. Ruszniewski, Role of hepatic intra-arterial therapies in metastatic neuroendocrine tumours (NET): guidelines from the NET-Liver-Metastases Consensus Conference, HPB (Oxford) 17(1) (2015) 29-37.

[72] M. Vyleta, D. Coldwell, Radioembolization in the treatment of neuroendocrine tumor metastases to the liver, International journal of hepatology 2011 (2011).

[73] K. Memon, R.J. Lewandowski, M.F. Mulcahy, A. Riaz, R.K. Ryu, K.T. Sato, R. Gupta, P. Nikolaidis, F.H. Miller, V. Yaghmai, Radioembolization for neuroendocrine liver metastases: safety, imaging, and long-term outcomes, International Journal of Radiation Oncology• Biology• Physics 83(3) (2012) 887-894.

[74] T.K. Rhee, R.J. Lewandowski, D.M. Liu, M.F. Mulcahy, G. Takahashi, P.D. Hansen, A.B. Benson, III, A.S. Kennedy, R.A. Omary, R. Salem, 90Y Radioembolization for Metastatic Neuroendocrine Liver Tumors: Preliminary Results From a Multi-institutional Experience, Annals of Surgery 247(6) (2008) 1029.

[75] B. Guiu, F. Deschamps, S. Aho, F. Munck, C. Dromain, V. Boige, D. Malka, S. Leboulleux, M. Ducreux, M. Schlumberger, Liver/biliary injuries following chemoembolisation of endocrine tumours and hepatocellular carcinoma: lipiodol vs. drug-eluting beads, Journal of hepatology 56(3) (2012) 609-617.

[76] H. Bergsma, E.I. van Vliet, J.J. Teunissen, B.L. Kam, W.W. de Herder, R.P. Peeters, E.P. Krenning, D.J. Kwekkeboom, Peptide receptor radionuclide therapy (PRRT) for GEP-NETs, Best Pract Res Clin Gastroenterol 26(6) (2012) 867-81.

[77] J.A. O'Donoghue, M. Bardies, T.E. Wheldon, Relationships between tumor size and curability for uniformly targeted therapy with beta-emitting radionuclides, J Nucl Med 36(10) (1995) 1902-9.

[78] L. Bodei, J. Mueller-Brand, R.P. Baum, M.E. Pavel, D. Horsch, M.S. O'Dorisio, T.M. O'Dorisio, J.R. Howe, M. Cremonesi, D.J. Kwekkeboom, J.J. Zaknun, The joint IAEA, EANM, and SNMMI practical guidance on peptide receptor radionuclide therapy (PRRNT) in neuroendocrine tumours, Eur J Nucl Med Mol Imaging 40(5) (2013) 800-16.

[79] J. Strosberg, G. El-Haddad, E. Wolin, A. Hendifar, J. Yao, B. Chasen, E. Mittra, P.L. Kunz, M.H. Kulke, H. Jacene, D. Bushnell, T.M. O'Dorisio, R.P. Baum, H.R. Kulkarni, M. Caplin, R. Lebtahi, T. Hobday, E. Delpassand, E. Van Cutsem, A. Benson, R. Srirajaskanthan, M. Pavel, J. Mora, J. Berlin, E. Grande, N. Reed, E. Seregni, K. Oberg, M. Lopera Sierra, P. Santoro, T. Thevenet, J.L. Erion, P. Ruszniewski, D. Kwekkeboom, E. Krenning, N.-T. Investigators, Phase 3 Trial of (177)Lu-Dotatate for Midgut Neuroendocrine Tumors, N Engl J Med 376(2) (2017) 125-135.

[80] A. Rinke, H.-H. Müller, C. Schade-Brittinger, K.-J. Klose, P. Barth, M. Wied, C. Mayer, B. Aminossadati, U.-F. Pape, M. Bläker, J. Harder, C. Arnold, T. Gress, R. Arnold, Placebo-Controlled, Double-Blind, Prospective, Randomized Study on the Effect of Octreotide LAR in the Control of Tumor Growth in Patients With Metastatic Neuroendocrine Midgut Tumors: A Report From the PROMID Study Group, Journal of Clinical Oncology 27(28) (2009) 4656-4663. [81] M.E. Caplin, J.R. Buscombe, A.J. Hilson, A.L. Jones, A.F. Watkinson, A.K. Burroughs, Carcinoid tumour, Lancet 352(9130) (1998) 799-805.

[82] T.A. Hope, J. Calais, L. Zhang, W. Dieckmann, C. Millo, (111)In-pentetreotide scintigraphy vs. (68)Ga-

DOTATATE PET: Impact on Krenning Scores and Effect of Tumor Burden, J Nucl Med (2019).

[83] D.L. Chan, N. Pavlakis, G.P. Schembri, E.J. Bernard, E. Hsiao, A. Hayes, T. Barnes, C. Diakos, M. Khasraw, J. Samra, E. Eslick, P.J. Roach, A. Engel, S.J. Clarke, D.L. Bailey, Dual Somatostatin Receptor/FDG PET/CT Imaging in Metastatic Neuroendocrine Tumours: Proposal for a Novel Grading Scheme with Prognostic Significance, Theranostics 7(5) (2017) 1149-1158.

[84] M.M. Graham, X. Gu, T. Ginader, P. Breheny, J.J. Sunderland, (68)Ga-DOTATOC Imaging of Neuroendocrine Tumors: A Systematic Review and Metaanalysis, J Nucl Med 58(9) (2017) 1452-1458. 
[85] M.S. Hofman, M. Michael, R. Kashyap, R.J. Hicks, Modifying the Poor Prognosis Associated with 18F-FDG-Avid NET with Peptide Receptor Chemo-Radionuclide Therapy (PRCRT), J Nucl Med 56(6) (2015) 968-9.

[86] S.P. Thang, M.S. Lung, G. Kong, M.S. Hofman, J. Callahan, M. Michael, R.J. Hicks, Peptide receptor radionuclide therapy (PRRT) in European Neuroendocrine Tumour Society (ENETS) grade 3 (G3) neuroendocrine neoplasia (NEN) a single-institution retrospective analysis, Eur J Nucl Med Mol Imaging 45(2) (2018) 262-277.

[87] S. Wulfert, C. Kratochwil, P.L. Choyke, A. Afshar-Oromieh, W. Mier, H.U. Kauczor, J.P. Schenk, U. Haberkorn, F.L. Giesel, Multimodal imaging for early functional response assessment of (90)Y-/ (177)Lu-DOTATOC peptide receptor targeted radiotherapy with DW-MRI and (68)Ga-DOTATOC-PET/CT, Mol Imaging Biol 16(4) (2014) 586-94. [88] T. Brabander, W.A. van der Zwan, J.J.M. Teunissen, B.L.R. Kam, R.A. Feelders, W.W. de Herder, C.H.J. van Eijck, G.J.H. Franssen, E.P. Krenning, D.J. Kwekkeboom, Long-Term Efficacy, Survival, and Safety of [\&lt;sup\&gt;177\&lt;/sup\&gt;Lu-DOTA\&lt;sup\&gt;0\&lt;/sup\&gt;,Tyr\&lt;sup\&gt;3\&lt;/sup\&gt;]octreotate in Patients with Gastroenteropancreatic and Bronchial Neuroendocrine Tumors, Clinical Cancer Research 23(16) (2017) 4617. [89] J.R. Strosberg, E.M. Wolin, B. Chasen, M.H. Kulke, D.L. Bushnell, M.E. Caplin, R.P. Baum, T.J. Hobday, A.E. Hendifar, K.E. Oberg, M. Lopera Sierra, D.J. Kwekkeboom, P.B. Ruszniewski, E. Krenning, P.L. Kunz, NETTER-1 phase III: Efficacy and safety results in patients with midgut neuroendocrine tumors treated with 177Lu-DOTATATE, Journal of Clinical Oncology 34(15_suppl) (2016) 4005-4005.

[90] J.R. Strosberg, E.M. Wolin, B.A. Chasen, M.H. Kulke, D.L. Bushnell, M.E. Caplin, R.P. Baum, T.J. Hobday, A.E. Hendifar, M. Lopera Sierra, K.E. Oberg, P.B. Ruszniewski, E. Krenning, First update on overall survival, progressionfree survival, and health-related time-to-deterioration quality of life from the NETTER-1 study: 177Lu-Dotatate vs. high dose octreotide in progressive midgut neuroendocrine tumors, Journal of Clinical Oncology 36(15_suppl) (2018) 40994099.

[91] A. Koumarianou, G. Kaltsas, M.H. Kulke, K. Oberg, J.R. Strosberg, F. Spada, S. Galdy, M. Barberis, C. Fumagalli, A. Berruti, Temozolomide in advanced neuroendocrine neoplasms: pharmacological and clinical aspects, Neuroendocrinology 101(4) (2015) 274-288.

[92] J.R. Strosberg, R.L. Fine, J. Choi, A. Nasir, D. Coppola, D.T. Chen, J. Helm, L. Kvols, First-line chemotherapy with capecitabine and temozolomide in patients with metastatic pancreatic endocrine carcinomas, Cancer 117(2) (2011) 26875.

[93] S. Ekeblad, A. Sundin, E.T. Janson, S. Welin, D. Granberg, H. Kindmark, K. Dunder, G. Kozlovacki, H. Orlefors, M. Sigurd, K. Oberg, B. Eriksson, B. Skogseid, Temozolomide as monotherapy is effective in treatment of advanced malignant neuroendocrine tumors, Clin Cancer Res 13(10) (2007) 2986-91.

[94] D. Martins, F. Spada, I. Lambrescu, M. Rubino, C. Cella, B. Gibelli, C. Grana, D. Ribero, E. Bertani, D. Ravizza, G. Bonomo, L. Funicelli, E. Pisa, D. Zerini, N. Fazio, I.E.C.o.E.f.G. NETs, Predictive Markers of Response to Everolimus and Sunitinib in Neuroendocrine Tumors, Target Oncol 12(5) (2017) 611-622.

[95] K. Oberg, O. Casanovas, J.P. Castaño, D. Chung, G. Delle Fave, P. Denèfle, P. Harris, M.S. Khan, M.H. Kulke, A. Scarpa, L.H. Tang, B. Wiedenmann, Molecular Pathogenesis of Neuroendocrine Tumors: Implications for Current and Future Therapeutic Approaches, Clinical Cancer Research 19(11) (2013) 2842.

[96] M. Dong, A.T. Phan, J.C. Yao, New Strategies for Advanced Neuroendocrine Tumors in the Era of Targeted Therapy, Clinical Cancer Research 18(7) (2012) 1830.

[97] J.E. Maxwell, S.K. Sherman, J.R. Howe, Translational Diagnostics and Therapeutics in Pancreatic Neuroendocrine Tumors, Clinical Cancer Research 22(20) (2016) 5022.

[98] B. Zhou, J. Xiang, C. Zhan, J. Liu, S. Yan, STK33 promotes the growth and progression of human pancreatic neuroendocrine tumour via activation of the PI3K/AKT/mTOR pathway, Neuroendocrinology (2019).

[99] S.P. Patel, M. Othus, Y.K. Chae, A Phase II basket trial of dual anti-CTLA-4 and anti-PD-1 blockade in rare tumors (DART) S1609: The neuroendocrine cohort, 2019.

[100] J.C. Yao, J. Strosberg, N. Fazio, M.E. Pavel, P. Ruszniewski, E. Bergsland, D. Li, S. Tafuto, N. Raj, D. Campana, 13080 Activity \& safety of spartalizumab (PDR001) in patients (pts) with advanced neuroendocrine tumors (NET) of pancreatic (Pan), gastrointestinal (GI), or thoracic (T) origin, \& gastroenteropancreatic neuroendocrine carcinoma (GEP NEC) who have progressed on prior treatment (Tx), Annals of Oncology 29(suppl_8) (2018) mdy293.001 \%@09237534.

[101] L. Dercle, F.Z. Mokrane, J.M. Schiano de Colella, A. Stamatoullas, F. Morschhauser, P. Brice, H. Ghesquieres, O. Casasnovas, A. Chen, G. Manson, R. Houot, Unconventional immune-related phenomena observed using 18F-FDG PET/CT in Hodgkin lymphoma treated with anti PD-1 monoclonal antibodies, Eur J Nucl Med Mol Imaging (2019). [102] L. Dercle, R.D. Seban, J. Lazarovici, L.H. Schwartz, R. Houot, S. Ammari, A. Danu, V. Edeline, A. Marabelle, V. Ribrag, J.M. Michot, (18)F-FDG PET and CT Scans Detect New Imaging Patterns of Response and Progression in Patients with Hodgkin Lymphoma Treated by Anti-Programmed Death 1 Immune Checkpoint Inhibitor, J Nucl Med 59(1) (2018) 15-24.

[103] L. Dercle, S. Ammari, R.-D. Seban, L.H. Schwartz, R. Houot, N. Labaied, F.-Z. Mokrane, J. Lazarovici, A. Danu, A. Marabelle, Kinetics and nadir of responses to immune checkpoint blockade by anti-PD1 in patients with classical Hodgkin lymphoma, European Journal of Cancer 91 (2018) 136-144 \%@ 0959-8049. 
[104] S. Champiat, L. Dercle, S. Ammari, C. Massard, A. Hollebecque, S. Postel-Vinay, N. Chaput, A. Eggermont, A. Marabelle, J.C. Soria, C. Ferte, Hyperprogressive Disease Is a New Pattern of Progression in Cancer Patients Treated by Anti-PD-1/PD-L1, Clin Cancer Res 23(8) (2017) 1920-1928.

[105] L. Dercle, S. Ammari, S. Champiat, C. Massard, C. Ferte, L. Taihi, R.D. Seban, S. Aspeslagh, L. Mahjoubi, N. Kamsu-Kom, C. Robert, A. Marabelle, M. Schlumberger, J.C. Soria, S. Postel-Vinay, Rapid and objective CT scan prognostic scoring identifies metastatic patients with long-term clinical benefit on anti-PD-1/-L1 therapy, Eur J Cancer 65 (2016) 33-42.

[106] L. Dercle, R. Chisin, S. Ammari, Q. Gillebert, M. Ouali, C. Jaudet, J.P. Delord, L. Dierickx, S. Zerdoud, M. Schlumberger, F. Courbon, Nonsurgical giant cell tumour of the tendon sheath or of the diffuse type: are MRI or 18FFDG PET/CT able to provide an accurate prediction of long-term outcome?, Eur J Nucl Med Mol Imaging 42(3) (2015) 397-408.

[107] A. Mekki, L. Dercle, P. Lichtenstein, A. Marabelle, J.M. Michot, O. Lambotte, J. Le Pavec, E. De Martin, C. Balleyguier, S. Champiat, S. Ammari, Detection of immune-related adverse events by medical imaging in patients treated with anti-programmed cell death 1, Eur J Cancer 96 (2018) 91-104.

[108] L. Seymour, J. Bogaerts, A. Perrone, R. Ford, L.H. Schwartz, S. Mandrekar, N.U. Lin, S. Litiere, J. Dancey, A. Chen, F.S. Hodi, P. Therasse, O.S. Hoekstra, L.K. Shankar, J.D. Wolchok, M. Ballinger, C. Caramella, E.G. de Vries, R.w. group, iRECIST: guidelines for response criteria for use in trials testing immunotherapeutics, Lancet Oncol 18(3) (2017) e143-e152.

[109] R. Yeh, L. Dercle, I. Garg, Z.J. Wang, D.M. Hough, A.H. Goenka, The Role of 18F-FDG PET/CT and PET/MRI in Pancreatic Ductal Adenocarcinoma, Abdom Radiol (NY) 43(2) (2018) 415-434.

[110] T. Kamisawa, K. Takum, H. Anjiki, N. Egawa, M. Kurata, G. Honda, K. Tsuruta, FDG-PET/CT findings of autoimmune pancreatitis, Hepato-gastroenterology 57(99-100) (2010) 447-450.

[111] K. Kato, T. Nihashi, M. Ikeda, S. Abe, S. Iwano, S. Itoh, K. Shimamoto, S. Naganawa, Limited Efficacy of 18FFDG PET/CT for Differentiation Between Metastasis-Free Pancreatic Cancer and Mass-Forming Pancreatitis, Clinical Nuclear Medicine 38(6) (2013) 417.

[112] I. Matsumoto, S. Shirakawa, M. Shinzeki, S. Asari, T. Goto, T. Ajiki, T. Fukumoto, K. Kitajima, Y. Ku, 18Fluorodeoxyglucose Positron Emission Tomography Does Not Aid in Diagnosis of Pancreatic Ductal Adenocarcinoma, Clinical Gastroenterology and Hepatology 11(6) (2013) 712-718.

[113] A.P. Rijkers, R. Valkema, H.J. Duivenvoorden, C.H.J. van Eijck, Usefulness of F-18-fluorodeoxyglucose positron emission tomography to confirm suspected pancreatic cancer: A meta-analysis, European Journal of Surgical Oncology (EJSO) 40(7) (2014) 794-804.

[114] L. Dercle, D. Deandreis, M. Terroir, S. Leboulleux, J. Lumbroso, M. Schlumberger, Evaluation of 124 I PET/CT and 124 I PET/MRI in the management of patients with differentiated thyroid cancer, European journal of nuclear medicine and molecular imaging 43(6) (2016) 1006-1010.

[115] A. Martinez-Moller, M. Souvatzoglou, G. Delso, R.A. Bundschuh, C. Chefd'hotel, S.I. Ziegler, N. Navab, M. Schwaiger, S.G. Nekolla, Tissue classification as a potential approach for attenuation correction in whole-body PET/MRI: evaluation with PET/CT data, Journal of nuclear medicine 50(4) (2009) 520.

[116] C. Kolbitsch, R. Neji, M. Fenchel, A. Mallia, P. Marsden, T. Schaeffter, Fully integrated 3D high-resolution multicontrast abdominal PET-MR with high scan efficiency, Magn Reson Med 79(2) (2018) 900-911.

[117] N. Fuin, O.A. Catalano, M. Scipioni, L.P.W. Canjels, D. Izquierdo-Garcia, S. Pedemonte, C. Catana, Concurrent Respiratory Motion Correction of Abdominal PET and Dynamic Contrast-Enhanced-MRI Using a Compressed Sensing Approach, J Nucl Med 59(9) (2018) 1474-1479.

[118] J. Yang, J. Liu, F. Wiesinger, A. Menini, X. Zhu, T.A. Hope, Y. Seo, P.E.Z. Larson, Developing an efficient phasematched attenuation correction method for quiescent period PET in abdominal PET/MRI, Phys Med Biol 63(18) (2018) 185002.

[119] L. Dercle, L. Lu, P. Lichtenstein, H. Yang, D. Wang, J. Zhu, F. Wu, H. Piessevaux, L.H. Schwartz, B. Zhao, Impact of Variability in Portal Venous Phase Acquisition Timing in Tumor Density Measurement and Treatment Response Assessment: Metastatic Colorectal Cancer as a Paradigm, JCO Clinical Cancer Informatics (1) (2017) 1-8. [120] L. Dercle, R. Chisin, S. Ammari, Q. Gillebert, M. Ouali, C. Jaudet, J.P. Delord, L. Dierickx, S. Zerdoud, M. Schlumberger, F. Courbon, Nonsurgical giant cell tumour of the tendon sheath or of the diffuse type: Are MRI or F-FDG PET/CT able to provide an accurate prediction of long-term outcome?, Eur J Nucl Med Mol Imaging (2014).

[121] L. Dercle, S. Ammari, M. Bateson, P.B. Durand, E. Haspinger, C. Massard, C. Jaudet, A. Varga, E. Deutsch, J.C. Soria, C. Ferte, Limits of radiomic-based entropy as a surrogate of tumor heterogeneity: ROI-area, acquisition protocol and tissue site exert substantial influence, Sci Rep 7(1) (2017) 7952.

[122] L.O. Dierickx, L. Dercle, L. Chaltiel, O. Caselles, S. Brillouet, S. Zerdoud, F. Courbon, Evaluation of 2 diuretic 18Fluorine-Fluorodeoxyglucose positron emission tomography/computed tomography imaging protocols for intra-pelvic cancer, Q J Nucl Med Mol Imaging (2017).

[123] R. Sun, E.J. Limkin, L. Dercle, S. Reuze, E.I. Zacharaki, C. Chargari, A. Schernberg, A.S. Dirand, A. Alexis, N. Paragios, E. Deutsch, C. Ferte, C. Robert, [Computational medical imaging (radiomics) and potential for immunooncology], Cancer Radiother 21(6-7) (2017) 648-654. 
[124] L. Dercle, D. Hartl, L. Rozenblum-Beddok, F.Z. Mokrane, R.D. Seban, R. Yeh, F. Bidault, S. Ammari, Diagnostic and prognostic value of 18F-FDG PET, CT, and MRI in perineural spread of head and neck malignancies, Eur Radiol 28(4) (2018) 1761-1770.

[125] X. Lin, L. Xu, A. Wu, C. Guo, X. Chen, Z. Wang, Differentiation of intrapancreatic accessory spleen from small hypervascular neuroendocrine tumor of the pancreas: textural analysis on contrast-enhanced computed tomography, Acta Radiologica (2018) 0284185118788895.

[126] C.B. van der Pol, S. Lee, S. Tsai, N. Larocque, A. Alayed, P. Williams, N. Schieda, Differentiation of pancreatic neuroendocrine tumors from pancreas renal cell carcinoma metastases on CT using qualitative and quantitative features, Abdominal Radiology (2019) 1-8.

[127] R. Canellas, K.S. Burk, A. Parakh, D.V. Sahani, Prediction of pancreatic neuroendocrine tumor grade based on CT features and texture analysis, American Journal of Roentgenology 210(2) (2018) 341-346.

[128] C. Guo, X. Zhuge, Z. Wang, Q. Wang, K. Sun, Z. Feng, X. Chen, Textural analysis on contrast-enhanced CT in pancreatic neuroendocrine neoplasms: association with WHO grade, Abdominal Radiology (2018) 1-10.

[129] W. Liang, P. Yang, R. Huang, L. Xu, J. Wang, W. Liu, L. Zhang, D. Wan, Q. Huang, Y. Lu, A Combined Nomogram Model to Preoperatively Predict Histologic Grade in Pancreatic Neuroendocrine Tumors, Clinical Cancer Research (2018).

[130] J. Li, J. Lu, P. Liang, A. Li, Y. Hu, Y. Shen, D. Hu, Z. Li, Differentiation of atypical pancreatic neuroendocrine tumors from pancreatic ductal adenocarcinomas: Using whole-tumor CT texture analysis as quantitative biomarkers, Cancer medicine 7(10) (2018) 4924-4931.

[131] B. Zhao, Y. Tan, W.-Y. Tsai, J. Qi, C. Xie, L. Lu, L.H. Schwartz, Reproducibility of radiomics for deciphering tumor phenotype with imaging, Scientific reports 6 (2016) 23428.

[132] Q. Huang, L. Lu, L. Dercle, P. Lichtenstein, Y. Li, Q. Yin, M. Zong, L. Schwartz, B. Zhao, Interobserver variability in tumor contouring affects the use of radiomics to predict mutational status, Journal of Medical Imaging 5(1) (2017) 011005. 


\section{TABLES}

Table 1: Imaging case report form: response to systemic cancer therapies

Abbreviations: FDG PET: Fluorodeoxyglucose Positron emission tomography, DOPA PET: dihydroxyphenylalanine Positron emission tomography, SSTR: somatostatin receptor, PD: progressive disease, SD: stable disease, PR: partial response, CR: complete response. 
$\square$ SSTR imaging

$\square$ FDG PET

$\square$ DOPA PET

Date of Baseline:

Date of nadir:

Previous treatment:
$\square$ Surgery
$\square$ Thermal ablation
$\square$ Liver embolization
$\square$ SIRT
$\square$ PRRT

$\square \quad$ Chemotherapeutic

regimens

$\square$ Targeted molecular agents

$\square$ Immunotherapy

Target lesions:

\begin{tabular}{|l|l|l|l|l|}
\hline & Location & Size & Density (HU) & SUV max \\
\hline Lesion 1 & & & & \\
\hline Lesion 2 & & & & \\
\hline Lesion 3 & & & & \\
\hline Lesion 4 & & & & \\
\hline Lesion 5 & & & & \\
\hline
\end{tabular}

Response compared to
Conclusion:
baseline
PD SD PR CR

Response compared to nadir

PD SD PR CR

\section{Response criteria}

\section{RECIST 1.1}

Cytotoxic

Choi

Cytostatic

No lesions detected

\section{iRECIST}

Immune therapy

All
and

metabolically active tumors 


\begin{tabular}{|c|c|c|c|c|}
\hline Partial response & $\begin{array}{l}->30 \% \text { decrease in sum of } \\
\text { longest diameters of target } \\
\text { lesions }\end{array}$ & $\begin{array}{l}\text { - } \geq 10 \% \text { decrease in } \\
\text { tumor size } \\
\text { - or } \geq 15 \% \text { decrease in } \\
\text { tumor attenuation at } \\
\mathrm{CT} \text {; } \\
\text { - no new lesion }\end{array}$ & $\begin{array}{l}->30 \% \text { decrease in sum of } \\
\text { longest diameters of target } \\
\text { lesions }\end{array}$ & $\begin{array}{l}\text {->30\% (0.8-unit) decline in } \\
\text { SUL peak between the most } \\
\text { intense lesion before treatment } \\
\text { and the most intense lesion } \\
\text { after treatment. }\end{array}$ \\
\hline Stable disease & None of the above & & & \\
\hline
\end{tabular}


Table 2. Indication of medical imaging modalities in GEP-NETS: part 1.

Abbreviations: IACIG: selective intra-arterial injection of calcium with hepatic venous insulin gradients; DOPA : dihydroxyphenylalanine, DOTATOC : DOTA ${ }^{0}-\mathrm{Phe}^{1}-\mathrm{Tyr}^{3}$ octreotide, SSTR scintigraphy: somatostatin receptor scintigraphy; PRRT: Peptide Receptor Radionuclide Therapy.

** Reconstruction < $3 \mathrm{~mm}$. Contrast-enhancement (acquisition: 15-25s after injection for angiography phase, 25-30s for portal-venous inflow phase, 70-90s for venous phase).

in and out of phase T1-weighted sequences. Transaxial dynamic gadolinium contrast-enhanced sequences with acquisition at 30, 70 and $120 \mathrm{~s}$ and at 3-5 min after the injection. Diffusion weighted imaging. 


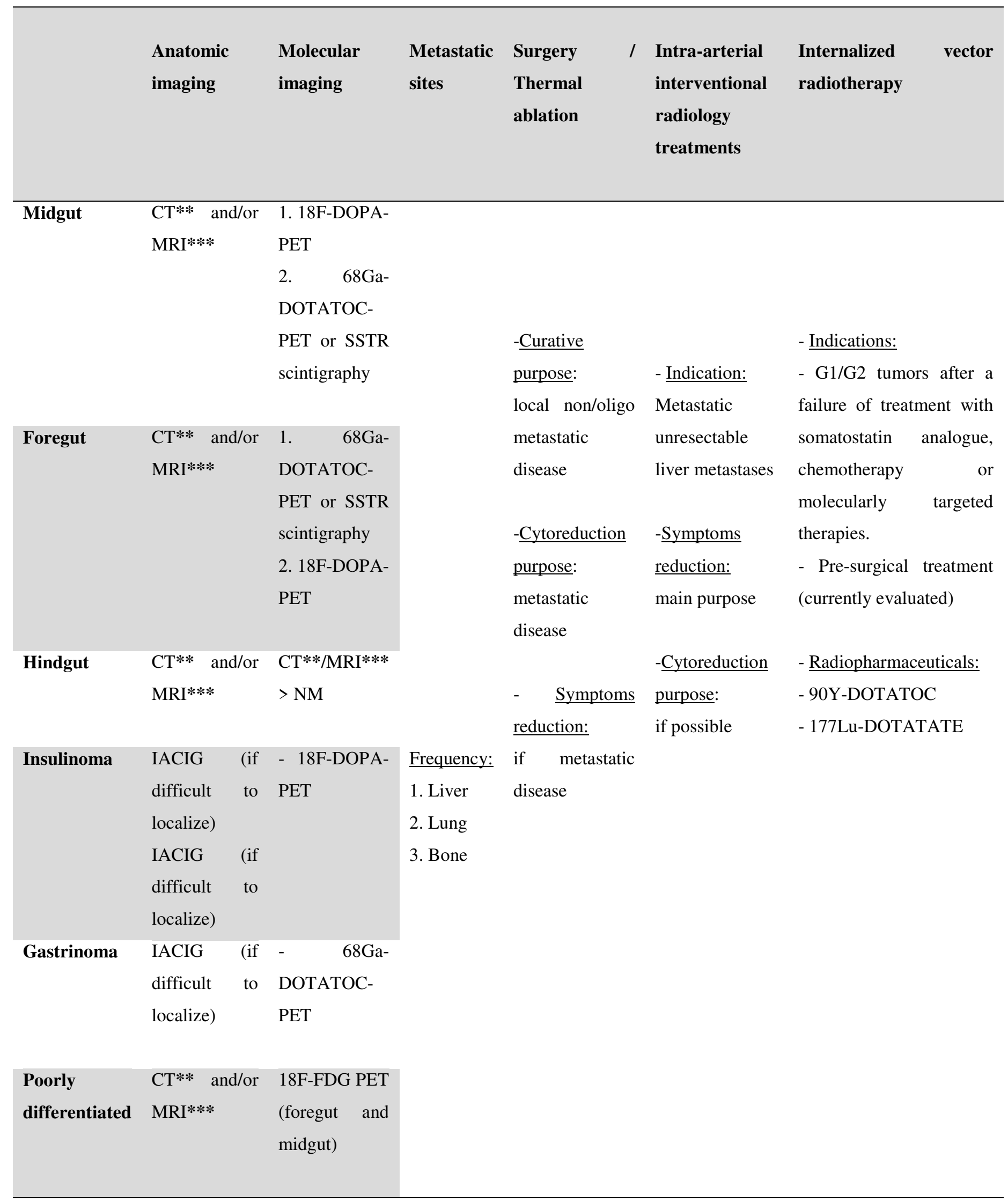




\section{FIGURE LEGENDS}

Fig. 1 Step by step imaging approaches for optimal management of unresectable P-NETs

Abbreviations: SSA: somatostatin analogs, If $\alpha$ : Interferon $\alpha, \mathrm{CT}$ : computed tomography; MRI: magnetic resonance imaging, FDG: Fluorodeoxyglucose, DOPA: dihydroxyphenylalanine, DOTATOC: DOTA ${ }^{0}-\mathrm{Phe}^{1}-\mathrm{Tyr}^{3}$ octreotide, SSTR scintigraphy: somatostatin receptor scintigraphy, SSTR: somatostatin receptor.

\section{Fig. 2 Nonfunctioning pNETS:}

Axial triphasic CT images illustrating incidental diagnoses of insulinoma and gastrinoma.

The insulinoma (a to c) is located at the body of the pancreas, but does not show the classical hyperenhancement pattern despite a slight hyperenhancement at the portal venous phase.

Axial and portal venous phases CT ( $d$ to f) clearly identified the extrapancreatic gastrinoma.

While the insulinoma is clearly locally resectable, the gastrinoma needs a careful evaluation of the adjacent anatomical structures (like the superior mesenteric vein) in order to assess local resectability.

\section{Fig. 3 Unresectable GEP net}

I: 50 years old male presented to radiology department in order to explore a chronic weight loss associated to abdominal pain. Axial $\left(a^{1}, a^{3}\right)$ and coronal $\left(a^{2}\right)$ enhanced CT confirmed the existence of a colonic wall thickening (yellow dotted circle), with several enlarged lymph nodes (yellow arrow). The patient presented also several liver lesions, showing all the same pattern: arterial hyperenhancement. The liver biopsy confirmed a grade II giNET.

II: 64 years old male presented to radiology department in order to explore a chronic abdominal pain and diarrhea. Coronal ( $b^{1}$ and axial $b^{2}$ enhanced CT confirmed the existence of an unresectable pancreatic mass (white arrow), associated to several secondary liver lesions (white arrowheads) and a partially calcified desmoplastic reaction (yellow dotted square).

In these two cases, the patients have clearly unresectable primitive lesion due to numerous liver lesions.

\section{Fig. 4 Importance of the radiotracer}

A 77 years old man with grade 2 (Ki67 between 15 and 20\%) rectal NET underwent three different types of tracers PET/CT modalities to study the disease spread within 10 days of interval. Because of the grade 2 status, a ${ }^{18} \mathrm{~F}-\mathrm{FDOPA}$ PET/CT $\left(a^{1}\right)$ was first performed but fused axial and sagittal images $\left(a^{2}, a^{3}, a^{4}\right)$ showed only a slight uptake of the primitive lesion (yellow arrow), no lesion in the hepatic parenchyma and only few minors uptakes in the vertebrae (yellow dot). ${ }^{68} \mathrm{Ga}$-DOTATOC PET/CT was then performed $\left(\mathrm{b}^{1}\right)$ : it showed a high uptake of the tracor in the rectal tumor $\left(b^{4}\right)$ Fused sagittal and axial images $\left(b^{2}, b^{3}\right)$ showed multiples hepatic and bone metastases. Because of the Ki67 $>10 \%$, an ${ }^{18} \mathrm{~F}$-FDG PET/CT was finally performed $\left(\mathrm{c}^{1}\right)$ : it showed less hepatic and bone metastases than the ${ }^{68} \mathrm{Ga}$-DOTATOC but probably lesions with the worst prognosis $\left(\mathrm{c}^{2}, \mathrm{c}^{4}\right)$. Interestingly, the left hepatic lesion with high uptake on ${ }^{18} \mathrm{~F}$-FDG $\left(c^{3}\right.$, black arrow) was hypometabolic on ${ }^{68} \mathrm{Ga}$-DOTATOC $\left(\mathrm{b}^{3}\right.$, black arrow) witnessing dedifferentiated cells within the lesion. 


\section{Fig. 5 Complementarity between anatomical and metabolic imaging}

54 years old men with a grade $1($ Ki67 $<2 \%)$ ileal NET had both anatomical and molecular imaging for initial staging of his disease: MRI (a), and CT (b) and 18F-FDOPA PET (c, $d$ and e). MRI and PET identified several liver lesions (orange arrows). However, very small arterial intra hepatic foci did not show a clear uptake on PET imaging (yellow dotted circles). MRI is very sensitive to liver lesions. 18F-FDOPA PET/CT demonstrates several bone metastases (d; punctiform radiotracor uptake on L4 vertebrae), that can not be diagnosed on CT (b) or MRI.

Multidisciplinary meeting decided to treat this patient with somatuline hormonotherapy.

\section{Fig. 6 Theranostic pathways actioned for management of GEP NETs}

Abbreviations: TKR: Tyrosine kinase receptor, EC: endothelial cell, PR: pericyte, CT: computed tomography, MRI: Magnetic resonance imaging, PRRT: peptide receptor radionuclide therapy

FDG: Fluorodeoxyglucose, SST: somatostatin.

\section{Fig. 7 role of metabolic imaging in "N" staging .}

A 35-years old woman presents with a Grade 3 pNET (Ki-67 of 25\%) at initial stating.

While MRI (including diffusion weighted imaging) did not identify liver lesions, several intra and retroperitoneal lymph nodes presented a high diffusion signal ( $a, b$, yellows circles) associated with a reduced ADC.

${ }^{18} \mathrm{~F}$ - FDG-PET/CT was performed in this patient with high grade pNET. It confirmed the pathological character of these lymph nodes (axial fused PET/CT, c,d, and MIP,e ; white circles), and allowed a better comprehension of the disease extend. In this case, baseline FDG-PET allows a complementary disease assessment, which is crucial for treatment planning.

\section{Fig. 8 Assessing unresectability using CT}

74 years old man, diagnosed with a PNET is addressed for baseline staging and treatment planning. The pancreatic mass is well-defined (yellow dotted curved line) on arterial (a) and portal venous phases (b). Moreover, the peritumoral infiltration (white arrows) concerns more than $180^{\circ}$ of the superior mesenteric artery (black dotted circle), precluding thus any surgical approach. There are several liver lesions compatible with liver metastasis, presenting with a central necrosis (star) both on arterial (c) and portal venous phases (d). Baseline CT also diagnoses an heterogeneous right ovarian mass (e), which increased in size 3 years later (f).

\section{Fig. 9 Tumoral thrombi highlighted by Octreoscan}

A 51 years old woman suffered from epigastric pain and hormonal syndrome. An enhanced axial CT $\left(\mathrm{a}^{1}\right)$ was performed, revealing a $67 \times 65 \mathrm{~mm}$ mass of the head of the pancreas with invasion of the adjacent vessels (cruoric thrombi of the inferior mesenteric vein and the portal vein). Biopsy revealed a grade 2 (Ki67 =5\%) pancreatic NET. An octreoscan (a) was then performed for staging. Axial fused images $\left(\mathrm{a}^{2}, \mathrm{a}^{3}\right)$ showed a large lesion of the pancreas with high expression of the SST2 receptors (Krenning score $=4$ ) associated with a highlighted tracor uptake in the portal vein, inferior mesenteric vein and splenic mesenteric vein, suggesting a tumoral invasion of the veins. Consequently, the patient could not been treated by surgery and benefits from chemotherapy (streptozotocine + doxorubicine). After 4 cycles of chemotherapy, CT $\left(b^{1}\right)$ showed a stable disease while maximum intensity projection (MIP) (b) and SPECT/CT octreoscan images $\left(b^{2}, b^{3}\right)$ revealed a partial response with a decreasing uptake of the pancreatic mass and of the vascular invasion. Due to the 
incomplete response after chemotherapy and high uptake on the octreoscan (Krenning score $=4$ ) the patient was eligible for targeted radionuclide therapy with Y90-DOTATOC and Lu 177-DOTATOC. Planar octreoscan image 1.5 years after the IVR showed a nearly complete metabolic response (c).

\section{Fig. 10 Liver metastases in pNET disease}

Fig 10, a to d: Axial T1-weighted MRI images without contrast (a), followed by arterial (c) and portal venous phases (c) and diffusion weighted images (d). Several small liver lesions can be distinguished (yellow arrows), presenting a rim enhancement, and a high signal on diffusion weighted images, consistent with liver metastases from pNET origin. Arterial phase and diffusion-weighted images better individualized the liver lesions than in portal phase, which individualized fewer lesions.

Fig 10, e and f: three years later, the patient presented an increased liver tumoral volume and was addressed for TACE. The angiography (e: arterial phase, f: delayed phase) confirms the existence on several liver lesions (yellow arrows), beyond any local treatment, confirming thus the indication of TACE. The persistence of the arterial enhancement at the delayed phase of angiography confirms the hyper-arterial character of these lesions.

Fig. 11 Intra-arterial interventional radiology for liver metastases of GEP nets: assessing response for TACE.

A 79 years old men with carcinoid syndrome due to liver metastases of a pancreatic neuroendocrine tumor, the liver mass was clearly identified on arterial phase CT (a : yellow dotted contours) and US (b).

The patient underwent TACE in order to reduce his symptomatology. The cone beam CT performed directly after TACE (coronal reconstruction, d) demonstrates the high lipiodol uptake in the tumors. CT examination performed 3 months later demonstrates morphological tumor response, characterized by a size reduction and a high lipiodol uptake (e). This radiological response was associated with a major decrease of the carcinoid syndrome.

\section{Fig. 12 Cytoreduction concept and combination of several imaging guided techniques.}

55 years old women with a resectable pNET had developed a unique liver metastasis (a, b: axial CT on arterial and venous phases, yellow dotted circle). The patient was treated by TACE regarding the size of the lesion (more than $4 \mathrm{~cm}$ ). The first control using CT (c) showed a partial response, with a clear reduction of the metastasis. However, a residual tumor was clearly identified (yellow arrow). The treatment was completed by thermal ablation (microwave, d). At 6 weeks follow up, no active lesion was remaining in the area of treatment (e).

\section{Fig. 13 Theranostic approach of a small bowel neuroendocrine tumor}

Patient with small bowel G1 neuroendocrine tumor $(\mathrm{Ki} 67=1 \%)$, initially treated by somatostatin analogs and small bowel resection due to bowel obstruction, presented with abdominal pain. A 68Ga- DOTATATE PET/CT showed elevated somatostatin receptor expression within lymph node, omental and liver metastases $\left(a^{1}, a^{2}\right)$. Hepatic MRI also showed multiple enhanced liver metastases $\left(\mathrm{a}^{3}\right)$. The patient stopped somatostatin analogs and received 4 cycles of Lu177 DOTATATE radionuclide therapy. Planar images 2.5 hours after Lu-177 DOTATATE infusion showed tumor targeting/localization of the radiopharmaceutical (b). 10 months later, 68Ga- DOTATATE PET/CT showed decreased radiotracer avidity with increased size of centrally necrotic liver lesions $\left(c^{1}, c^{2}\right)$. MRI showed increasing size due to necrosis of liver lesions, with decreasing viable enhancing peripheral soft tissue $\left(c^{3}\right)$. 


\section{Fig. 14 68Ga-DOTATOC PET can select patients for IVR}

68Ga-DOTATOC PET-CT performed (a, MIP) for staging of a 60 year old woman with ileal G1 NET : images showed thyroid ( $\mathrm{b}^{1}$; fused axial PET/CT, $\mathrm{b}^{2}$ : axial PET, $\mathrm{b}^{3}:$ axial CT), hepatic and peritoneal metastasis $\left(\mathrm{c}^{1}\right.$ : fused axial PET/CT, $\mathrm{c}^{2}$ : axial PET, $\mathrm{c}^{3}:$ axial CT), (red arrows). Histological confirmation was performed for the thyroid metastase. Due to the high tracor uptake (Krenning score $=3$ ), the patient was eligible for IRV with Luthatera. 
Fig.1

\begin{tabular}{|c|c|c|c|c|c|}
\hline CLASSIFICATION & & G1 NET & G2 NET & G3 NET & G3 NEC \\
\hline \multirow[t]{3}{*}{ BIOPSY } & Differentiation & Well & Well & Well & Poorly \\
\hline & Ki 67 & $<3 \%$ & $3-20 \%$ & $>20 \%$ & $>20 \%$ \\
\hline & Mitotic index & $<3 \%$ & $3-20 \%$ & $>20 \%$ & $>\mathbf{2 0} \%$ \\
\hline \multicolumn{6}{|l|}{ IMAGING } \\
\hline \multirow{3}{*}{$\begin{array}{l}\text { Midgut: DOPA }>\text { SRS or DOTATOC } \\
\text { Foregut: DOTATOC }>\text { SRS } \\
\text { Hindgut: CT or MRI }>\text { Molecular imaging }\end{array}$} & $\mathrm{CT} / \mathrm{MR}$ & \multicolumn{4}{|c|}{ High contrast enhancement at arterial phase } \\
\hline & SR imaging & & & & \\
\hline & DOPA imaging & & & & \\
\hline
\end{tabular}

\section{RESECTABLE / CYTOREDUCTION}

- Resectable primitive, resectable liver mets: curative

--.. Unresectable primitive and/or unresectable liver mets: palliative cytoreduction

UNRESECTABLE: THERAPIES

Unresecteable small intestine NETs Unresecteable paNETs or recurrence of small intestine NETs

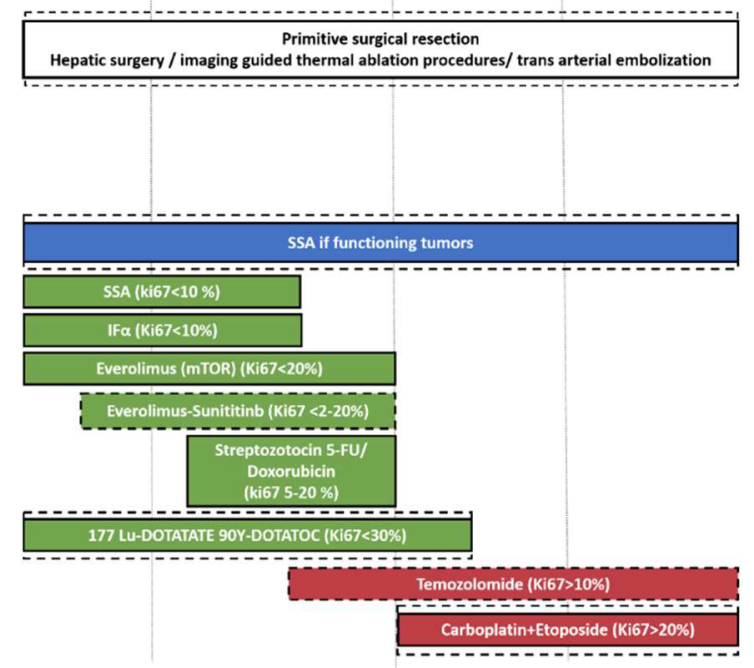


Fig. 2

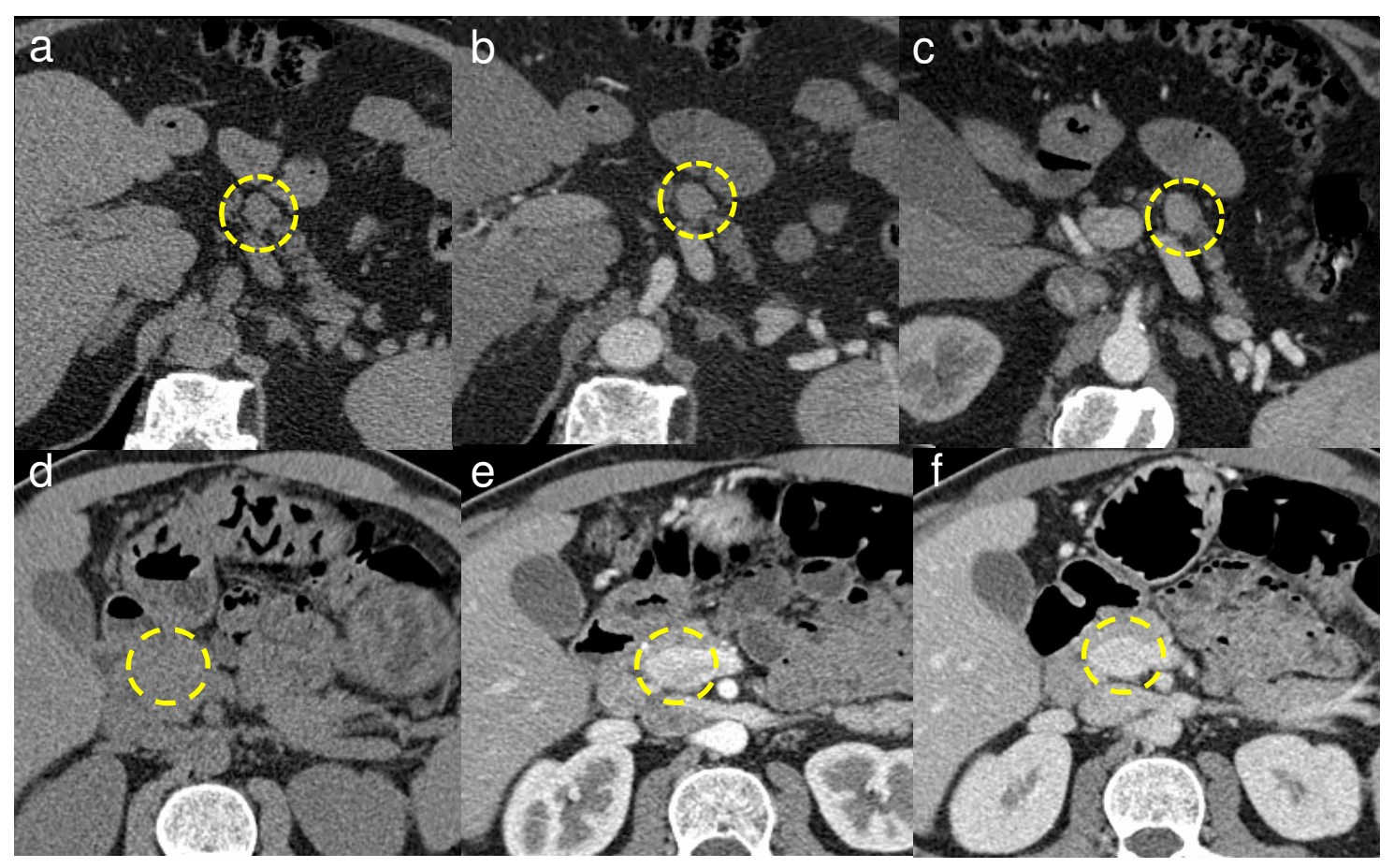


Fig. 3

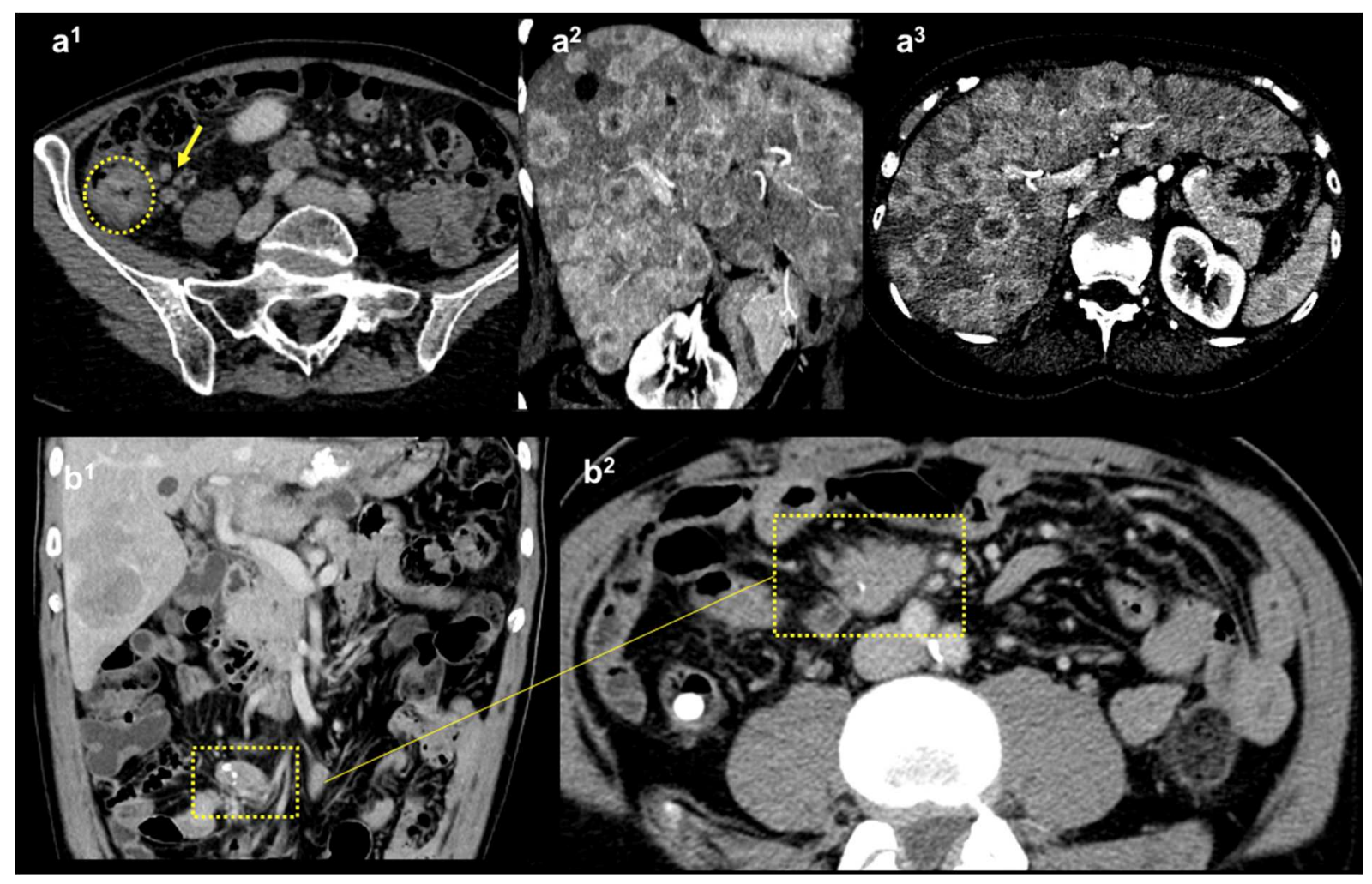


Fig. 4

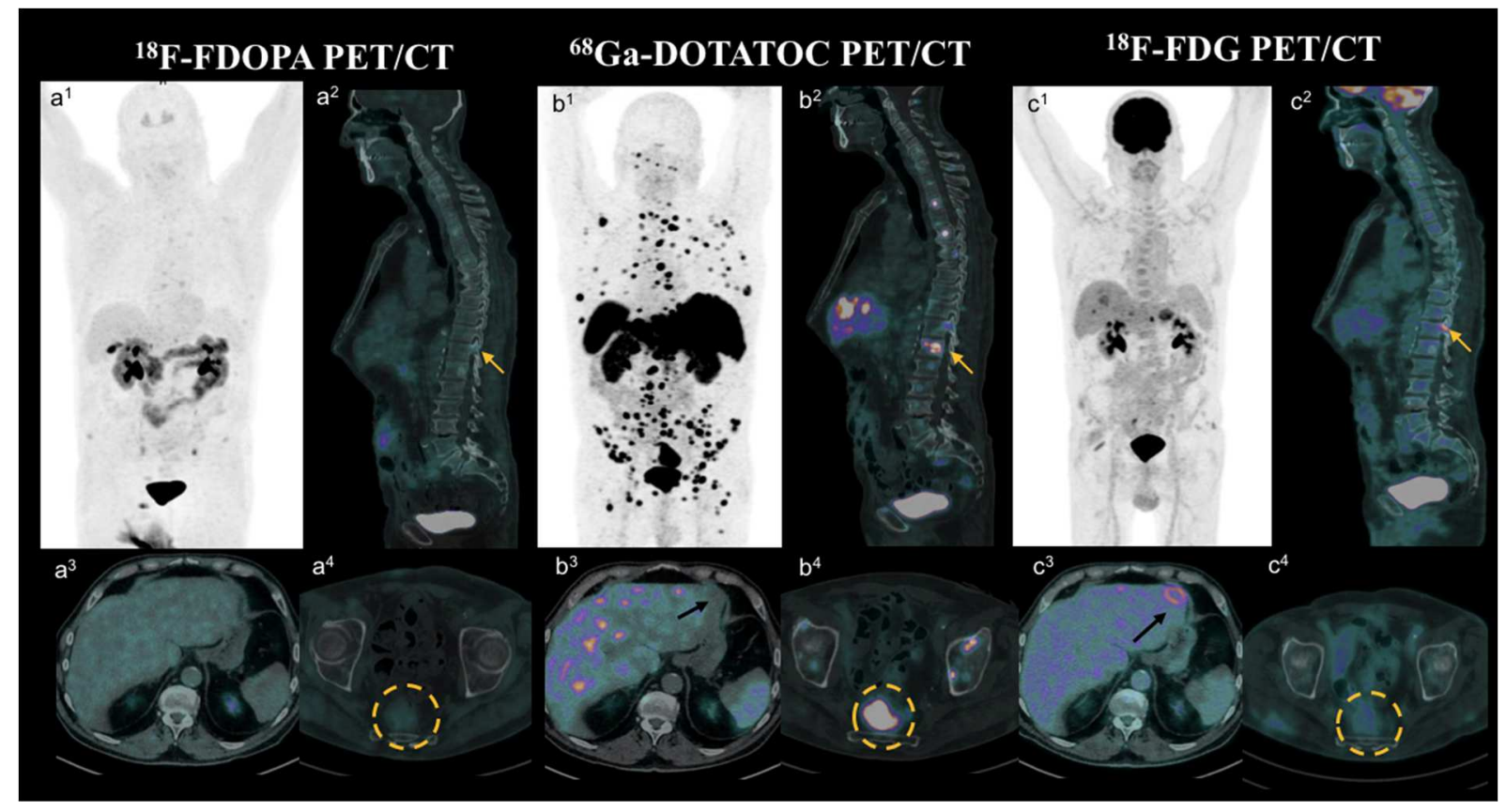


Fig. 5

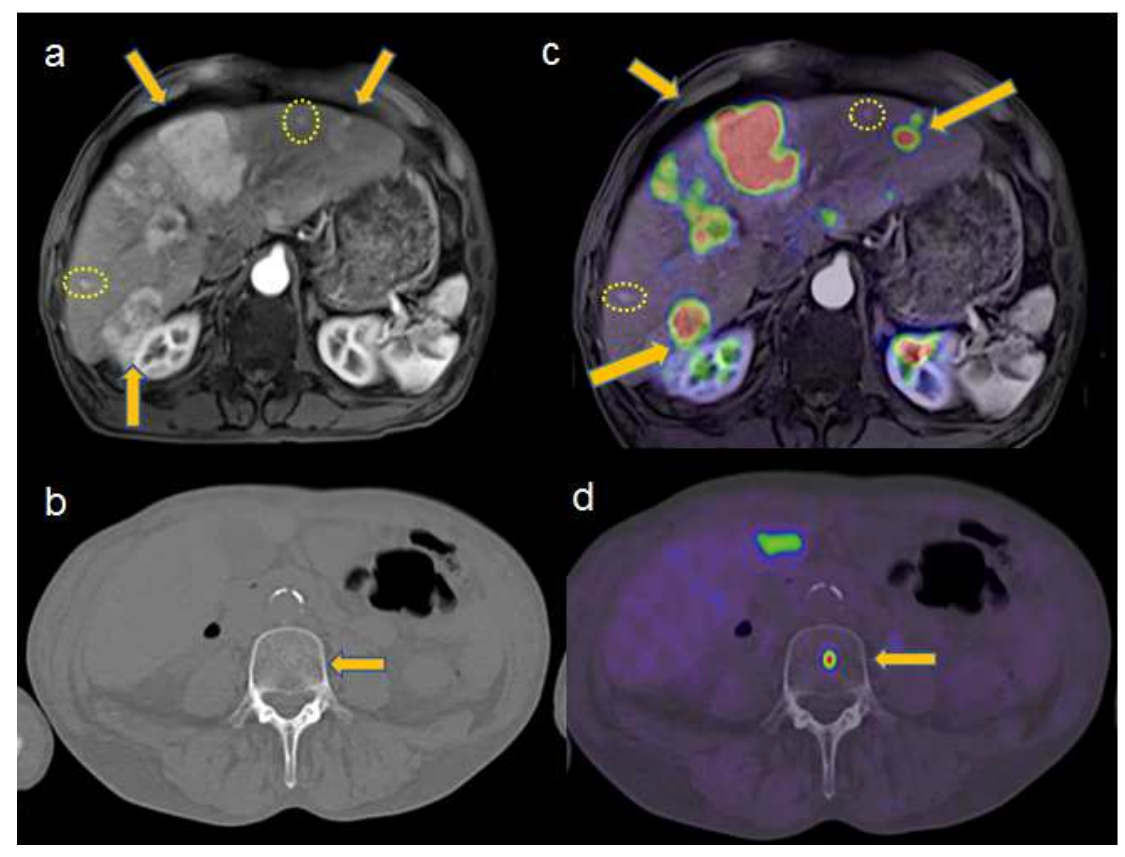

e

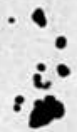

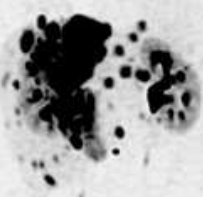


Fig.6

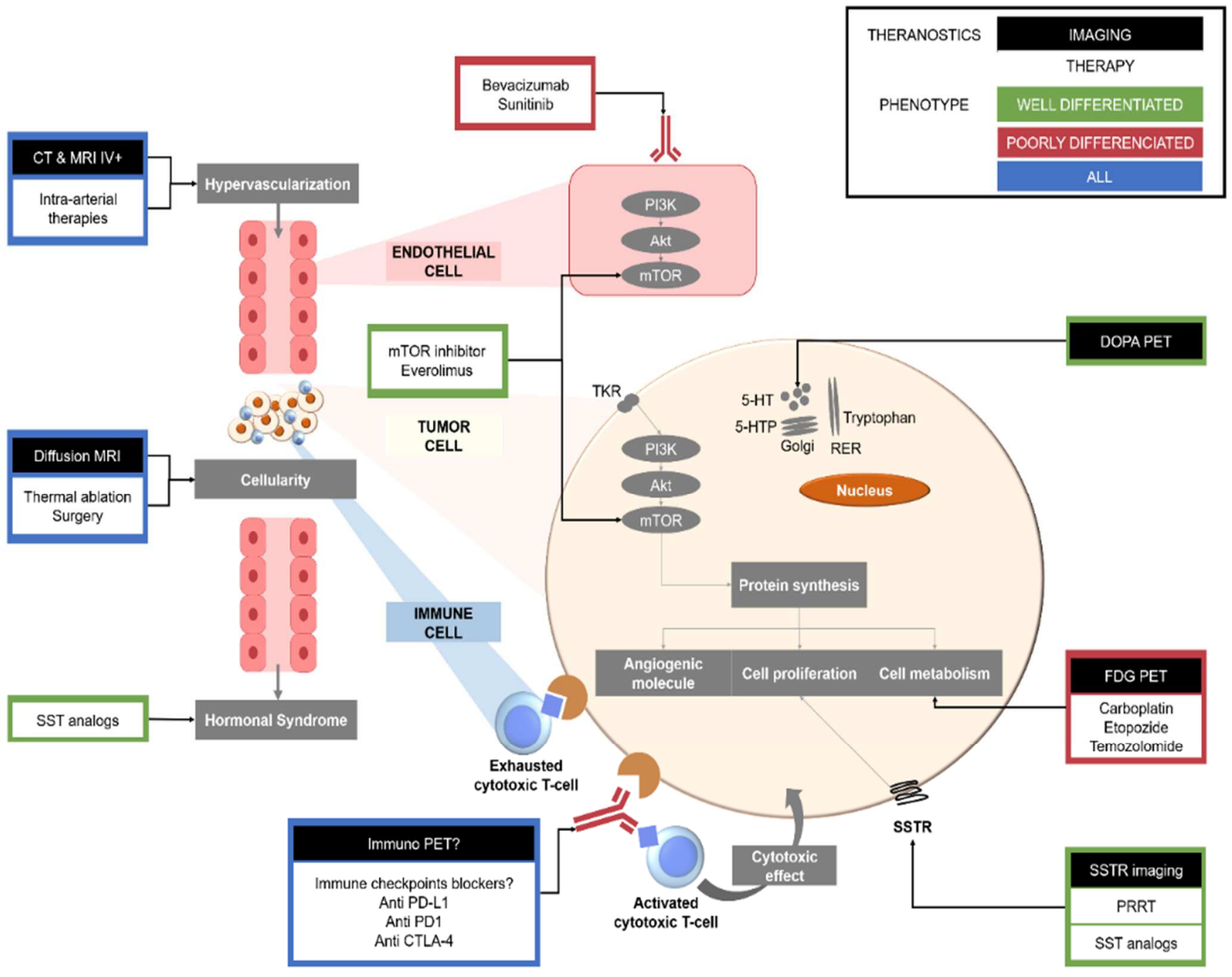


Fig.7

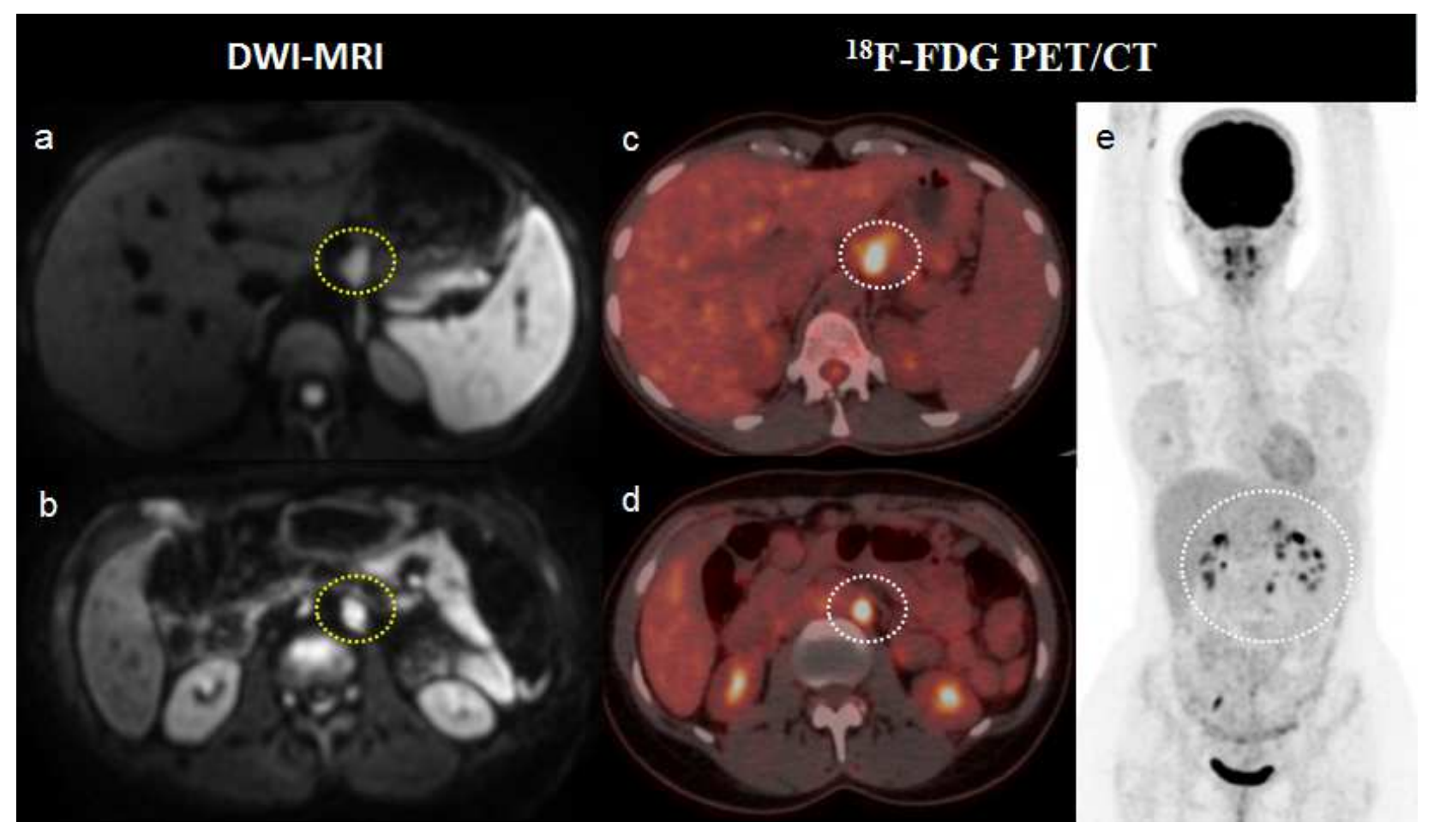


Fig. 8

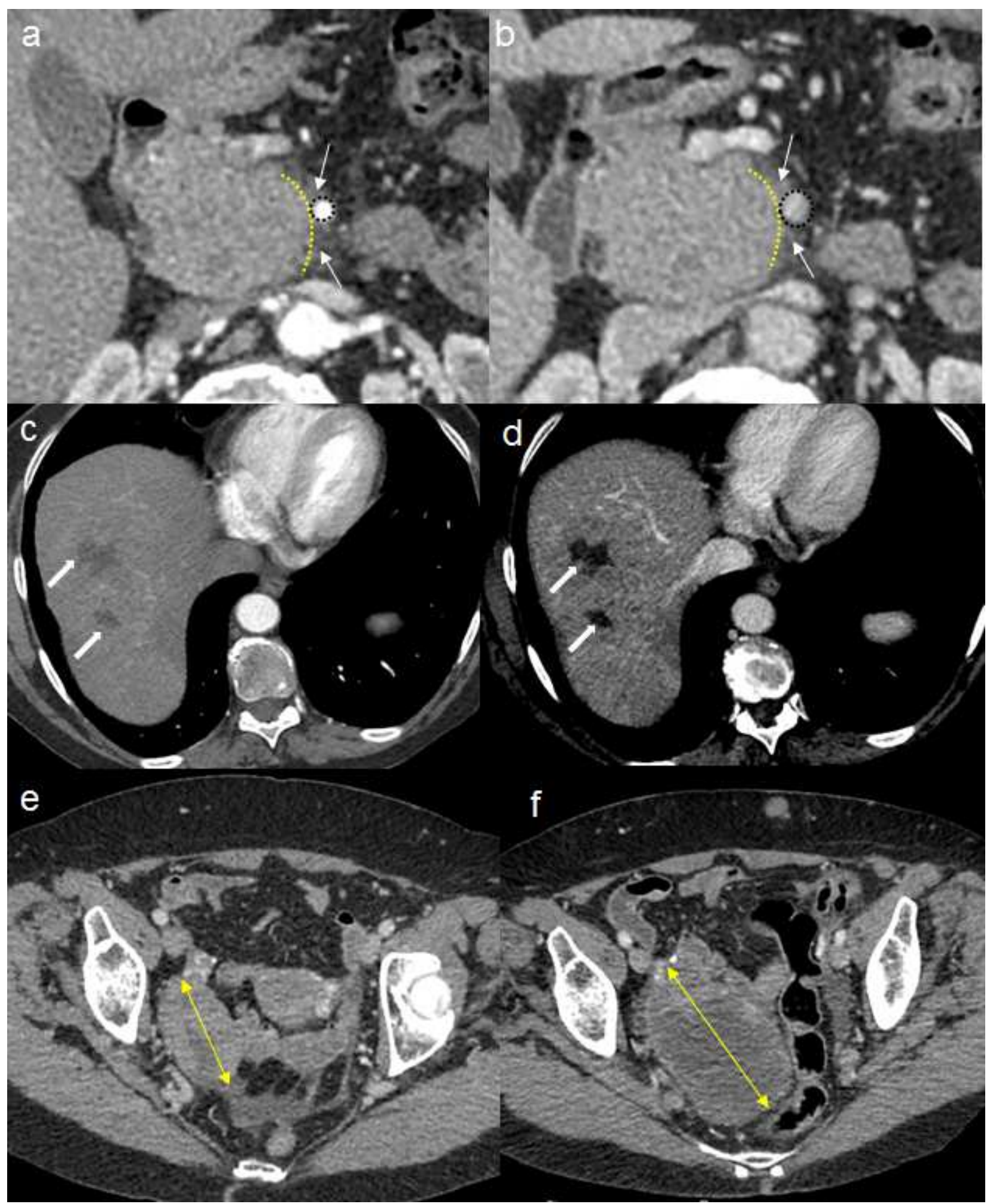


Fig .8

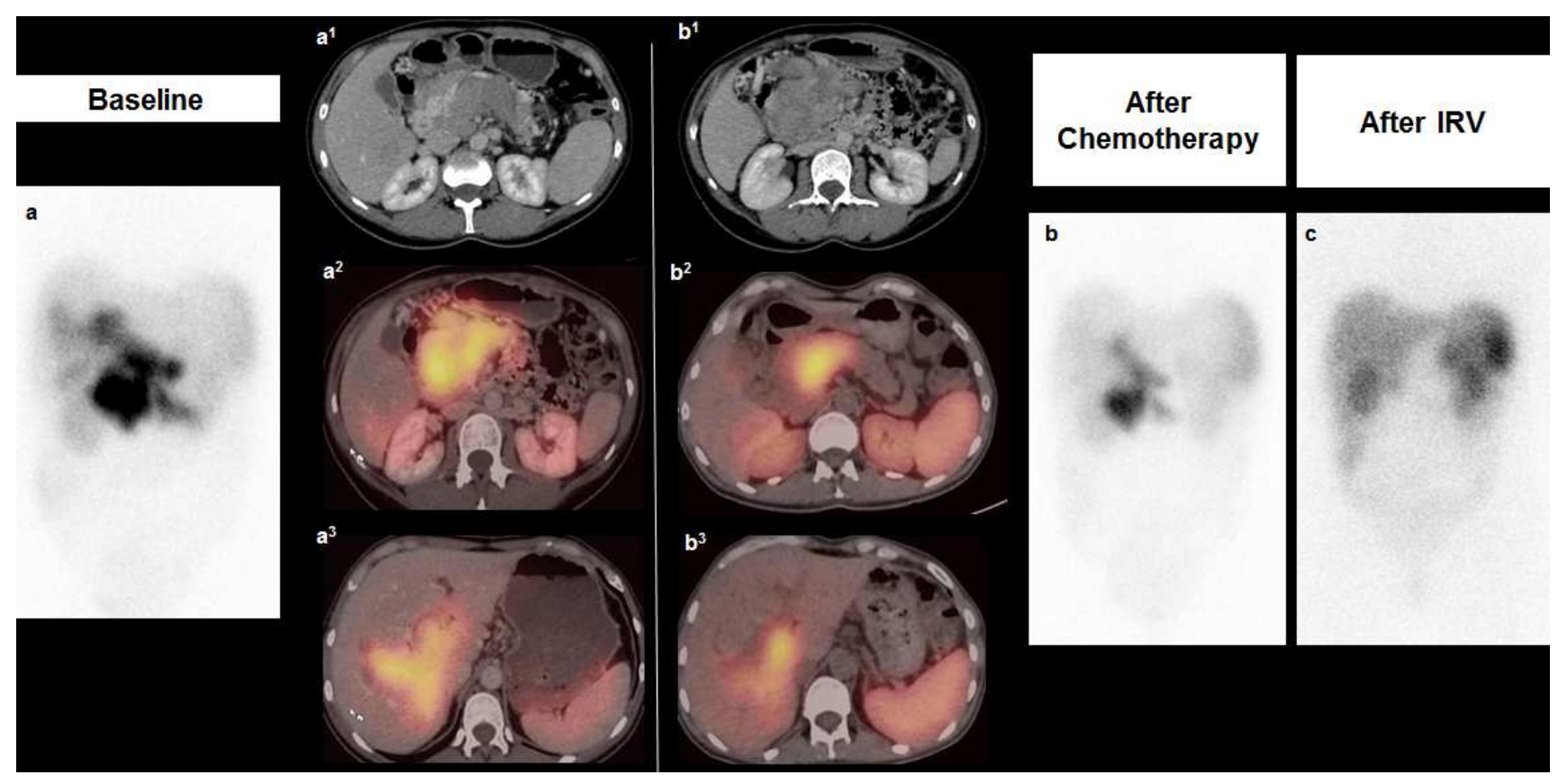


Fig. 10

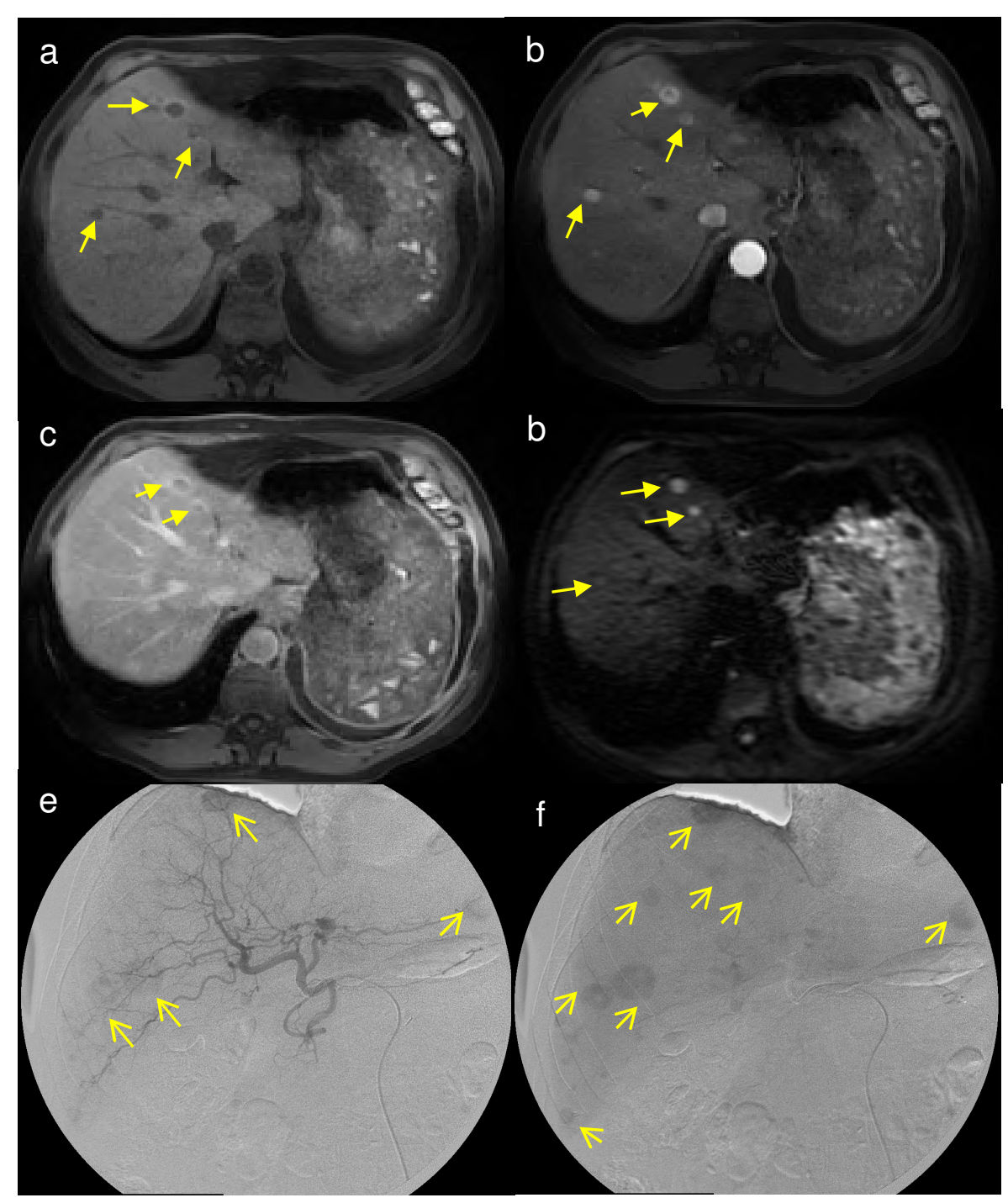


Fig. 11

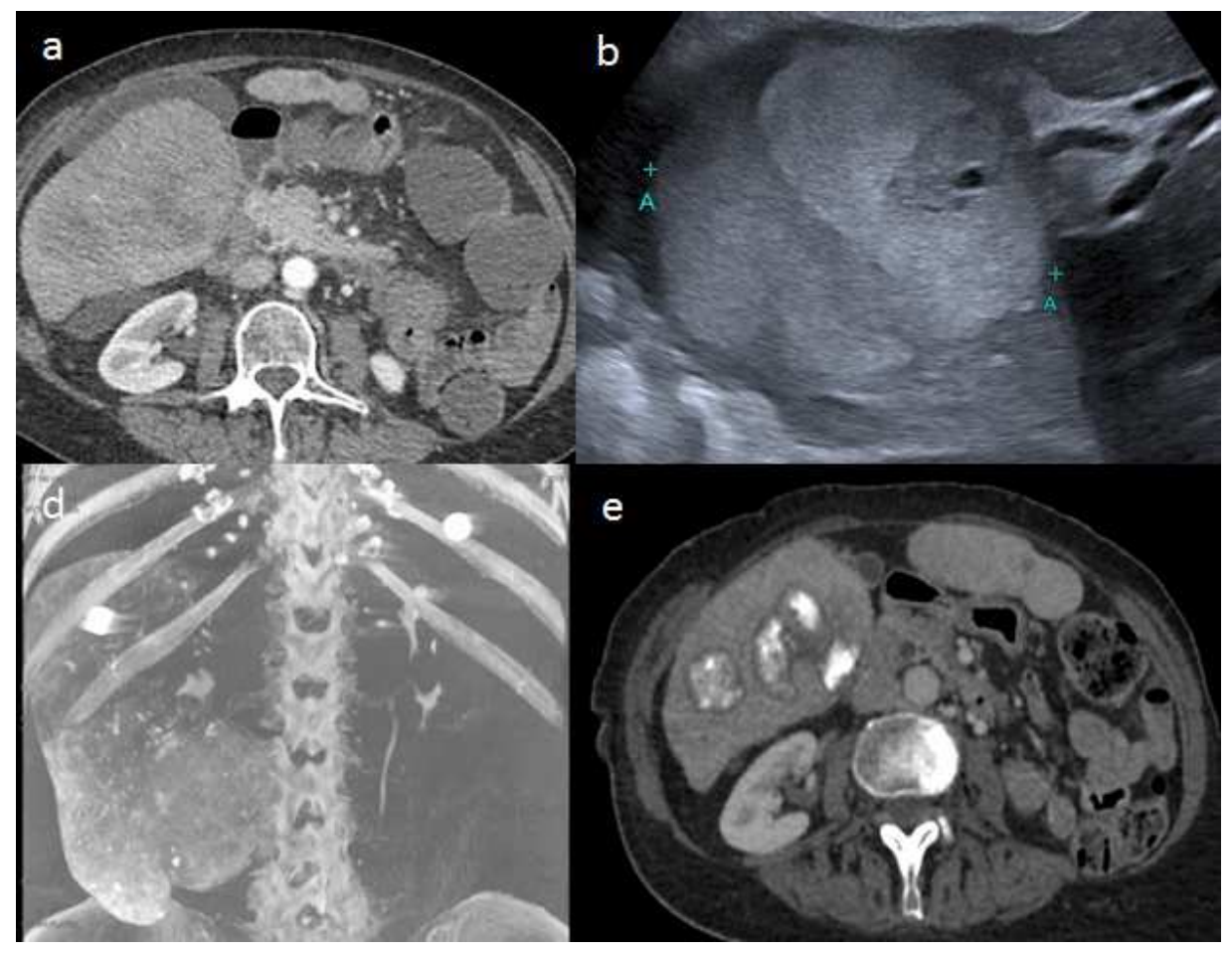


Fig. 12

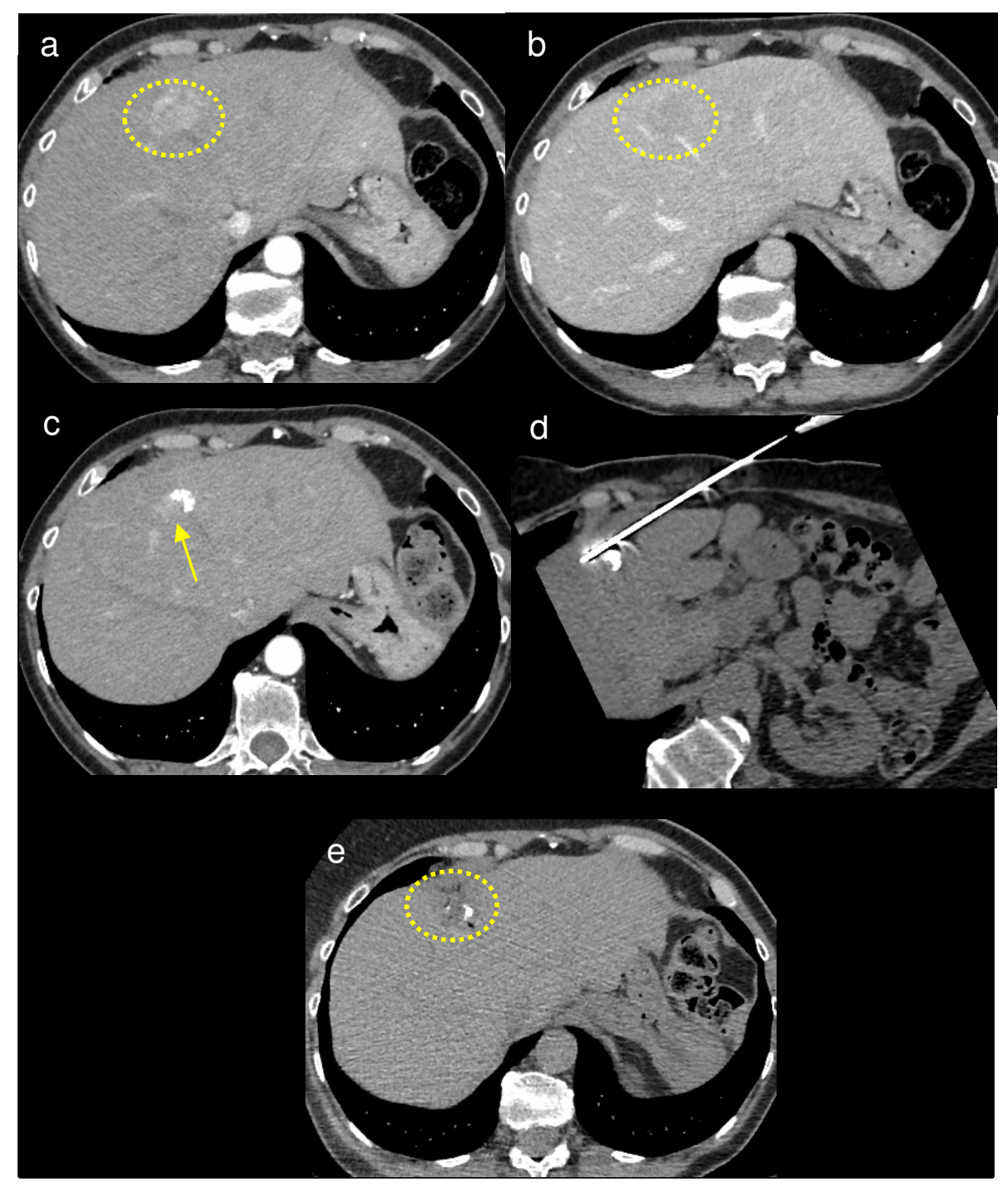


Fig. 13

a

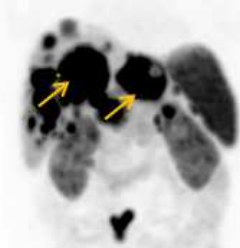

.
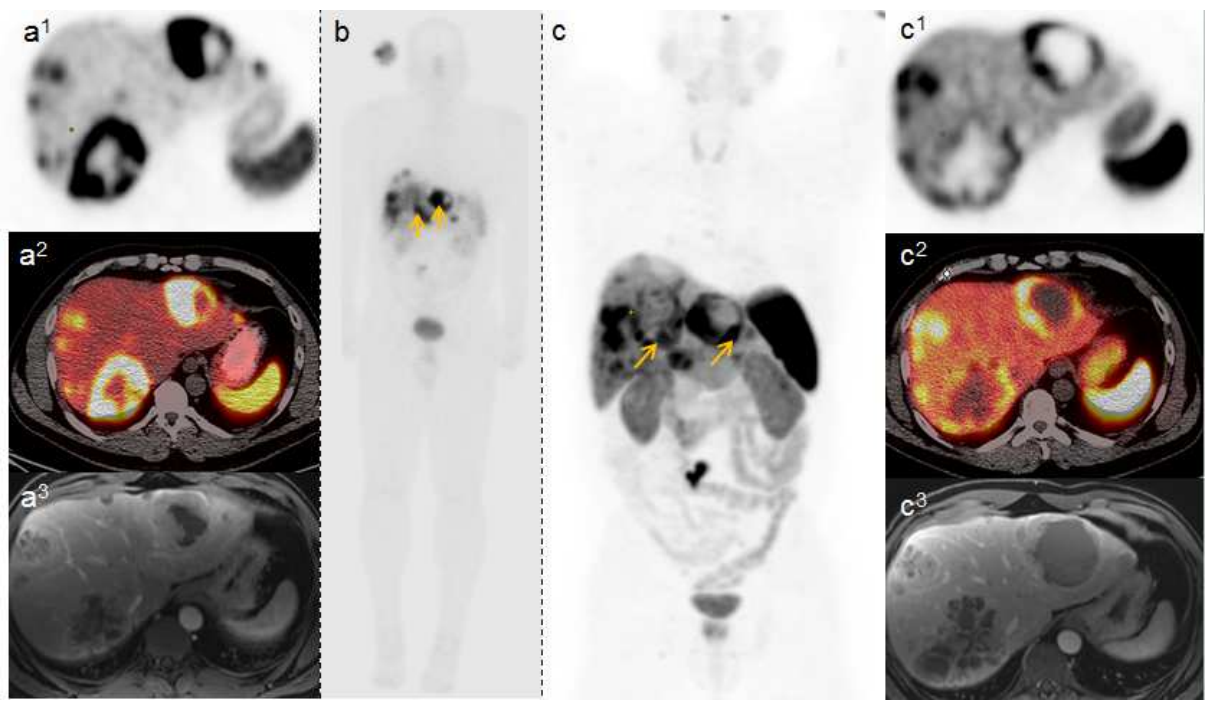
Fig. 14

a

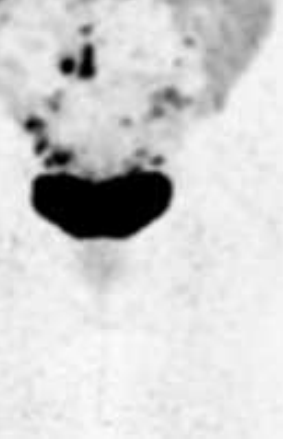

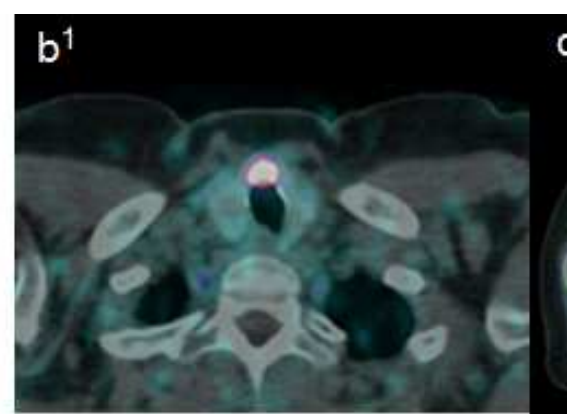

$c^{1}$

$b^{2}$

$$
c^{2}
$$
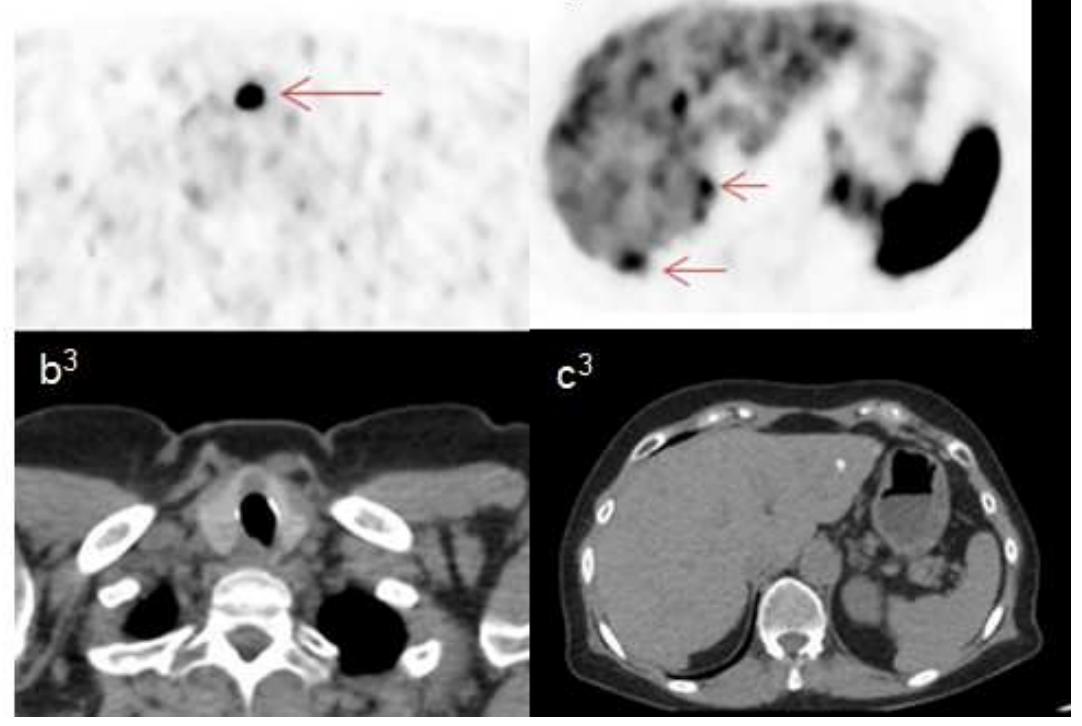